\title{
Urokinase-Type Plasminogen Activator Promotes Dendritic Spine Recovery and Improves Neurological Outcome Following Ischemic Stroke
}

\author{
Fang Wu, ${ }^{1 \star}$ Marcela Catano, ${ }^{1 \star}$ Ramiro Echeverry, ${ }^{1 \star}$ Enrique Torre, ${ }^{1}$ Woldeab B. Haile, ${ }^{1}$ Jie An, ${ }^{1,2}$ Changhua Chen, ${ }^{1}$ \\ Lihong Cheng, ${ }^{1}$ Andrew Nicholson, ${ }^{3}$ Frank C. Tong, ${ }^{4}$ Jaekeun Park, ${ }^{5}$ and $\odot$ Manuel Yepes ${ }^{1,6}$ \\ ${ }^{1}$ Department of Neurology and Center for Neurodegenerative Disease, Emory University School of Medicine, Atlanta, Georgia 30322, 2 Department of \\ Pharmacology, Shandong University School of Medicine, 250100 Jinan, China, ${ }^{3}$ Department of Radiology and Imaging Sciences and ${ }^{4}$ Departments of \\ Radiology and Neurosurgery, Emory University School of Medicine, Atlanta, Georgia 30322, 5 Wallace H. Coulter Department of Biomedical Engineering, \\ Emory University, Atlanta, Georgia 30322, and 'Department of Neurology, Veterans Affairs Medical Center, Atlanta, Georgia 30349
}

Spines are dendritic protrusions that receive most of the excitatory input in the brain. Early after the onset of cerebral ischemia dendritic spines in the peri-infarct cortex are replaced by areas of focal swelling, and their re-emergence from these varicosities is associated with neurological recovery after acute ischemic stroke (AIS). Urokinase-type plasminogen activator (uPA) is a serine proteinase that plays a central role in tissue remodeling via binding to the urokinase plasminogen activator receptor (uPAR). We report that cerebral cortical neurons release uPA during the recovery phase from ischemic stroke in vivo or hypoxia in vitro. Although uPA does not have an effect on ischemia- or hypoxia-induced neuronal death, genetic deficiency of $\mathrm{uPA}\left(\mathrm{uPA}^{-I-}\right)$ or $\mathrm{uPAR}\left(\mathrm{uPAR}^{-l-}\right)$ abrogates functional recovery after AIS. Treatment with recombinant uPA after ischemic stroke induces neurological recovery in wild-type and $\mathrm{uPA}^{-l-}$ but not in $\mathrm{uPAR}^{-1-}$ mice. Diffusion tensor imaging studies indicate that $\mathrm{uPA}^{-1-}$ mice have increased water diffusivity and decreased anisotropy associated with impaired dendritic spine recovery and decreased length of distal neurites in the peri-infarct cortex. We found that the excitotoxic injury induces the clustering of uPAR in dendritic varicosities, and that the binding of uPA to uPAR promotes the reorganization of the actin cytoskeleton and re-emergence of dendritic filopodia from uPAR-enriched varicosities. This effect is independent of uPA's proteolytic properties and instead is mediated by Rac-regulated profilin expression and cofilin phosphorylation. Our data indicate that binding of uPA to uPAR promotes dendritic spine recovery and improves functional outcome following AIS.

Key words: cerebral ischemia; recovery; stroke; urokinase-type plasminogen activator

\section{Introduction}

Ischemic stroke is a leading cause of disability in the world (Go et al., 2014). Every year millions of stroke victims survive with variable degrees of restrictions in their daily living, and while $15 \%$ of patients die after the stroke, $10 \%$ have complete recovery in their neurological function, 25\% recuperate with minor impairment, $40 \%$ are left with moderate to severe deficits, and 10\% have functional compromise severe enough to require long-term care (NSA, 2013).

Experimental evidence indicates that structural and functional reorganization in the peri-infarct tissue underlies the re-

Received Dec. 19, 2013; revised Sept. 6, 2014; accepted Sept. 11, 2014.

Author contributions: F.C.T. and M.Y. designed research;F.W., M.C., R.E., E.T., W.B.H., J.A., C.C., L.C., A.N., and J.P. performed research; F.C.T. contributed unpublished reagents/analytic tools; F.C.T. and M.Y. analyzed data; M.Y. wrote the paper.

This work has been supported in part by National Institutes of Health Grants NS-062073 (to M.Y.) and NS-079331 (to M.Y.) and VA Merit Award BX000474 (to M.Y.).

*F.W., M.C., and R.E. contributed equally to this work.

The authors declare no competing financial interests.

Correspondence should be addressed to Manuel Yepes, Department of Neurology and Center for Neurodegenerative Disease, Emory University, Whitehead Biomedical Research Building, 615 Michael Street, Suite 505J, Atlanta, GA 30322.E-mail: myepes@emory.edu.

DOI:10.1523/JNEUROSCI.5309-13.2014

Copyright $\odot 2014$ the authors $\quad 0270-6474 / 14 / 3414219-14 \$ 15.00 / 0$ covery process following an ischemic stroke (Carmichael, 2006). It has been demonstrated that the area surrounding the necrotic core may take over the function of other areas lost to stroke (Jaillard et al., 2005), and that post-stroke behavioral deficits can be reinstated by ablation of the peri-infarct tissue (CastroAlamancos and Borrel, 1995). However, despite its importance, the biochemical events underlying the reorganization of the periinfarct cortex remain unclear.

Dendritic spines are protrusions that receive most of the excitatory synapses in the CNS (Kasai et al., 2003). Cerebral ischemia has a direct impact on the integrity of these structures. Indeed, two landmark in vivo studies using two-photon microscopy showed that whereas dendritic spines inside the necrotic core are irreversibly damaged, those located within $0.6 \mathrm{~mm}$ from its border are replaced by areas of focal swelling, known as dendritic varicosities; remarkably, if reperfusion occurs within 60 min of the onset of the ischemic injury, a variable proportion of spines in this area re-emerge again from these varicosities (Zhang et al., 2005; Li and Murphy, 2008). This highly plastic nature of dendritic spines bestows on them a fundamental role in the recovery process from an ischemic stroke (Brown et al., 2007; Murphy and Corbett, 2009). 
Urokinase-type plasminogen activator (uPA) is a serine proteinase that, on binding to the urokinase plasminogen activator receptor (UPAR), is cleaved by membrane-bound plasmin and other proteases to produce an active two-chain form that catalyzes the conversion of plasminogen into plasmin. UPAR is a glycosylphosphatidylinositol-anchored glycoprotein that promotes tissue remodeling, inflammation, chemotaxis, cell proliferation, adhesion, and migration via its interaction with a large number of proteins in the extracellular matrix and cell surface (Alfano et al., 2005). uPA has been found in neurons in the cerebral cortex (Dent et al., 1993); however, its function in the CNS remains unclear.

The studies presented here indicate that cerebral cortical neurons release uPA during the recovery phase from acute ischemic and hypoxic injuries. This uPA does not have an effect on neuronal survival; instead it promotes the development of structural changes in the peri-infarct tissue that leads to neurological recovery following an ischemic stroke. More specifically, our data indicate that uPA binding to uPAR promotes dendritic spine recovery in the peri-infarct tissue via Rac-mediated reorganization of their actin cytoskeleton. These results show a novel role for uPA in the CNS and identify uPA/uPAR as a potential target for the development of therapeutic strategies to promote recovery in the ischemic brain.

\section{Materials and Methods}

Animals and reagents. Animal strains were 8- to 12 week-old uPAdeficient $\left(\mathrm{uPA}^{-1-}\right)$ and uPAR-deficient $\left(\mathrm{uPAR}^{-1-}\right)$ male mice on a C57BL/6J background and their Wt littermate controls (a generous gift from Dr. Thomas H. Bugge, Oral and Pharyngeal Cancer Branch, National Institute of Dental and Craniofacial Research-National Institutes of Health, Bethesda, MD). We also used a mouse strain developed by Dr. Bugge on a C57BL/6J background (Plau ${ }^{G F D h u / G F D h u}$; Connolly et al., 2010), in which a 4 aa substitution into the growth factor domain of uPA abrogates its binding to UPAR while preserving other functions of the protease and its receptor. Experiments were approved by the Institutional Animal Care and Use Committee of Emory University, Atlanta, GA. Recombinant murine uPA and uPA's N-terminal fragment (ATF) were purchased from Molecular Innovations. An ELISA kit that detects uPA was obtained from Cell Sciences. Other reagents were 3-(4,5dimethylthiazol-2-yl)-2,5-diphenyltetrazolium bromide (MTT) assay (ATCC); triphenyl tetrazolium chloride (TTC), Evans blue dye, and antiMAP-2 antibodies (Sigma); the lipophilic tracer DiI and rhodaminephalloidin (Life Technologies); Golgi staining (FD Neurotechnologies); NMDA (Calbiochem); the ROCK inhibitor Y-27632 (blocks ROCK-I and ROCK-II; Millipore); the Rac inhibitor EHT-1864 (blocks Rac 1, RAc 1b, Rac 2, and Rac 3; Tocris Bioscience); and antibodies against uPAR (Santa Cruz Biotechnology), synaptophysin (Millipore), and cofilin phosphorylated at serine 3 (Cell Signaling Technology). Antibodies against profilin were purchased from Cytoskeleton.

Animal model of cerebral ischemia. Transient occlusion of the middle cerebral artery (tMCAO) was induced with a 6-0 silk suture advanced from the external carotid artery (ECA) into the internal carotid artery until the origin of the middle cerebral artery (MCA) as described previously (Wu et al., 2012). Briefly, a nylon monofilament (6-0, Ethicon), coated with silicone was introduced through the ECA and advanced up to the origin of the MCA. The suture was withdrawn after $30 \mathrm{~min}$ or $60 \mathrm{~min}$ of cerebral ischemia. Cerebral perfusion (CP) in the distribution of the MCA was monitored throughout the surgical procedure and after reperfusion with a laser Doppler (Perimed), and only animals with a $>70 \%$ decrease in $\mathrm{CP}$ after occlusion and complete recovery after suture withdrawn were included in this study. The rectal and masseter muscle temperatures were controlled at $37^{\circ} \mathrm{C}$ with a homoeothermic blanket. Heart rate and systolic, diastolic, and mean arterial blood pressures were controlled throughout the surgical procedure with an IITC 229 System (IITC-Lice Science). To measure the volume of the ischemic lesion, brains of $\mathrm{uPA}^{-1-}$ mice and their Wt littermate controls $(n=12)$ were harvested $24 \mathrm{~h}$ after tMCAO and the volume of infarcted brain was measured in TTC-stained sections and corrected for edema as described previously (Swanson et al., 1990). To quantify the extent of vasogenic edema $\mathrm{Wt}$ and $\mathrm{uPA}^{-1-}$ mice $(n=8$ per strain) were intravenously injected with $1 \mathrm{ml}$ of Evans blue dye immediately after tMCAO. Twentyfour hours later animals were transcardially perfused, brains were harvested, and the concentration of Evans blue dye was quantified as described previously (Yepes et al., 2003).

Neuronal cultures and determination of neuronal survival. Cerebral cortical neurons were cultured from E16-E18 Wt, uPA ${ }^{-1-}$, and $\mathrm{uPAR}^{-1-}$ mice as described previously(Echeverry et al., 2010). Briefly, the cerebral cortex was dissected, transferred into HBSS containing $100 \mathrm{U} / \mathrm{ml}$ penicillin, $100 \mu \mathrm{g} / \mathrm{ml}$ streptomycin, and $10 \mathrm{~mm}$ HEPES, and incubated in trypsin containing $0.02 \% \mathrm{DNase}$ at $37^{\circ} \mathrm{C}$ for $15 \mathrm{~min}$. Tissue was triturated and the supernatant was resuspended in B27-supplemented Neurobasal medium containing $2 \mathrm{~mm}$ L-glutamine and plated onto $0.1 \mathrm{mg} / \mathrm{ml}$ polyL-lysine-coated wells. To determine cell survival neurons were kept in an anaerobic chamber (HypOxygen) during $55 \mathrm{~min}$ with no glucose and $<0.1 \%$ oxygen. Twenty-four hours later cell survival was quantified with the MTT assay as described previously and following manufacturer's instructions (Echeverry et al., 2010). Results are given as a percentage of cell survival compared with cultures maintained under normoxic conditions. Each experiment was performed in cultures from three different animals and each observation was repeated 20 times.

Determination of $u P A$ concentration. The culture medium of Wt cerebral cortical neurons was sampled after 30 and $55 \mathrm{~min}$ of exposure to oxygen and glucose deprivation (OGD) conditions, and 3-24 h after the end of 55 min of OGD ( $n=12$ observations per time point; each experiment was repeated with neurons cultured from three different animals). The ischemic brain tissue of Wt mice was harvested $30 \mathrm{~min}$ or $60 \mathrm{~min}$ after the onset of MCAO, or 1-24 h after 60 min of tMCAO $(n=8$ observations per time point). The concentration of uPA was measured in the culture media and ischemic brain tissue with an ELISA kit, following manufacturer's instructions.

Corner test, laterality index, and forelimb strength test. $\mathrm{Wt}, \mathrm{uPA}^{-1-}$, and $\mathrm{uPAR}^{-1-}$ mice $(n=20$ per strain) underwent tMCAO followed 6, 24, 48, 72 , and $168 \mathrm{~h}(7 \mathrm{~d})$ later by evaluation of their performance in the corner test and determination of the forelimb strength. A subgroup of mice of each strain ( $n=15$ per strain) was intra-arterially (IA) treated immediately after tMCAO with $0.1 \mathrm{mg} / \mathrm{kg}$ ruPA. The corner test was performed as described previously(Bouët et al., 2007). Briefly, two vertical boards $(30 \times 20 \times 1 \mathrm{~cm})$ were attached at an angle of $30^{\circ}$ and with a small opening between the boards, which encouraged the mouse to go into the corner. Mice were placed at the entry of the corner and when they reached its wedge, vibrissae and skin on both sides were simultaneously stimulated. The mouse usually reared and turned either to the right or to the left. Each mouse was tested for 10 trials and the chosen sides were noted. When the mouse turned without rearing, the trial was not taken into account but repeated at the end of the session. Only turns involving full rearing along either side were recorded. The laterality index (LI) was calculated for each mouse, according to the following formula:

Number of left turns - Number of right turns

Total number of turns

A positive or negative LI refers to predominance of turns to the left or the right side, respectively. To limit interindividual variability, a baseline LI (Lib) was obtained before surgery for each animal. For the post-tMCAO evaluations, the LI obtained at each time point was normalized to the Lib of each mouse, according to the following equation:

$$
\frac{\mathrm{LI}+2}{\mathrm{Lib}+2}
$$

A normalized LI equal to 1 indicates unchanged performance compared with baseline evaluation, whereas a value close to 2 or 0 indicates a tendency to perform more ipsilateral (left) or contralateral (right) turns. Values are given as mean of normalized LI at each time point. The forelimb grip strength was measured using a grip-strength meter (Bioseb) 
before surgery and $24,48,72$, and $168 \mathrm{~h}$ (7 d) after tMCAO as previously described (Wu et al., 2012). Mice were allowed to grasp a smooth metal, triangular pull bar with the digits of their right forelimb and then pulled backward in the horizontal plane. The force applied to the bar at the moment when the grasp was released was recorded as the peak tension in Newtons. Each test was repeated five times and the mean of all trials was recorded as the mean grip strength in the affected forepaw for that animal. For both tests values are given as a percentage compared with results obtained in the baseline evaluation for each animal.

Diffusion tensor imaging and determination of fractional anisotropy and mean diffusivity of water. The brains of $\mathrm{Wt}$ and $\mathrm{uPA}^{-1-}$ mice $(n=6 \mathrm{per}$ strain) were harvested $24 \mathrm{~h}$ after MCAO. Ex vivo MRI was performed on a Bruker 9.4 Thorizontal scanner using a $35 \mathrm{~mm}$ volume coil (Bruker). A gradient insert (inner diameter: $60 \mathrm{~mm}$ ) capable of generating a maximum of $1000 \mathrm{mT} / \mathrm{m}$ was used. Diffusion tensor imaging (DTI) data were acquired using a 3D conventional spin-echo DTI sequence. The DTI parameters were as follows: TE/TR $=22 / 1200 \mathrm{~ms}, \mathrm{~b}=800 \mathrm{~s} / \mathrm{mm}^{2}$, gradient separation/duration $(D / d)=12 / 4 \mathrm{~ms}, \mathrm{FOV}=20.5 \times 11.5 \times$ $11.5 \mathrm{~mm}^{3}, 2$ average, matrix $=128 \times 72 \times 72$, resolution $=160 \mu \mathrm{m}$ isotropic. The fractional anisotropy (Fa) and mean diffusivity (MD) of water were examined in an area located within $0.6 \mathrm{~mm}$ from the border of the necrotic core in the ischemic hemisphere, and from a comparable area in the contralateral nonischemic hemisphere (Paxinos and Franklin, 2001). The mean length of distal neuronal extensions ( $n=2000$ extensions per animal) was determined in the same area only in the ischemic hemisphere. Quantifications were performed with software from the Oxford Center for Functional Magnetic Resonance Imaging of the Brain's Software Library (http://www.fmrib.ox.ac.uk/fsl/). Color coding of Fa images was performed with MedINRIA and data were analyzed with the FMRIB Software Library v5.0. For the MD and Fa each measurement was repeated three times in each section, and normalized to values obtained in an identical area in the contralateral, nonischemic hemisphere in each animal. To measure tract length two seeds were placed at 0.1 and $0.6 \mathrm{~mm}$ from the border of the necrotic core in the same region of interest used to quantify changes in dendritic spine density in Golgi-stained sections. Tractography was performed with a threshold of 2000 tracts with the DSI studio software as described previously (Jiang et al., 2006; Wang et al., 2012). Each measurement was repeated eight times in each animal.

DiI staining and in vitro model of recovery from an excitotoxic injury. DiI staining was performed in brain sections and neuronal cultures. For DiI staining in tissue, the brain of $\mathrm{Wt}$ and $\mathrm{uPA}^{-1-}$ mice $(n=3$ per strain) was harvested $24 \mathrm{~h}$ after tMCAO, embedded in $3 \%$ agarose, cut onto coronal sections, and incubated with microcrystals of DiI as described previously (Kim et al., 2007). Sections were visualized using a Zeiss LSM510 NLO with META confocal microscope. Images of DiI-stained dendrites located within $0.6 \mathrm{~mm}$ of the border of the necrotic core were collected using a $568 \mathrm{~nm}$ laser and a TRITC emission filter with Zen 2009 Zeiss software. $Z$-series were acquired at $0.3 \mu \mathrm{m}$ increments. Individual dendrites and dendritic protrusions were deconvolved and 3D reconstructed using Imaris (Bitplane Scientific Software). Filaments were created using Autopath mode of a region within $0.6 \mathrm{~mm}$ from the border of the necrotic core in neurons originated in the $\mathrm{V}$ cortical layer harboring $50-100 \mu \mathrm{m}$ distal dendrites. We used $0.75-1 \mu \mathrm{m}$ as minimum dendrite end diameter and the starting point was chosen at the edge of the ROI. Automatic thresholds were used for assigning dendrite end points and dendrite surface rendering. To trace dendritic protrusions, the maximum spine length and the minimum spine end diameter were set at 5 and $0.25 \mu \mathrm{m}$. Automatic thresholds were used for generating spine seed points and surface rendering as described previously (Swanger et al., 2011). For DiI staining in neuronal cultures we modified two published protocols (Honig and Hume, 1989a,b). Briefly, Wt cerebral cortical neurons were washed and incubated during 10 min with $10 \mu \mathrm{M}$ NMDA dissolved in HEPES- and bicarbonate-buffered salt solution (HBBSS). NMDA exposure was terminated by replacing the solution with NMDAfree HBBSS media. Cultures were incubated during 90 min with the fluorescent tracer DiI ( $5 \mu \mathrm{g} / \mathrm{ml}$ in HBBSS), either immediately after the end of $10 \mathrm{~min}$ of NMDA exposure (acute injury), or $3 \mathrm{~h}$ after NMDA withdrawing (recovery phase). Low-magnification images of distal dendrites were obtained with a fluorescence microscope (Zeiss AxioCam), imported into AxioVision, and viewed at $200 \%$ of the original $20 \times$ image with Image MetaMorph Software. The number of protrusions per $10 \mu \mathrm{m}$ in the distal dendrite, including dendritic spines and filopodia (thin dendritic protrusions with a length $>2 \mu \mathrm{m}$ and lack of a bulbous head), was determined by a blind observer in 10 neurons in each coverslip. Each observation was repeated in six coverslips for a total $n=60$ per experimental group. Each experiment was repeated in cultures from three different animals.

Golgi staining. $\mathrm{uPA}^{-1-}, \mathrm{uPAR}^{-/-}, \mathrm{Plau}^{\text {GFDhu/GFDhu }}$, and $\mathrm{uPA}^{-1-}$ mice and their Wt littermate controls ( $n=12$ per time point) were either sham operated or subjected to MCAO. Six, 24, and $168 \mathrm{~h}$ (7 d) later, animals were transcardially perfused with $1.5 \%$ paraformaldehyde and brains were harvested and immersed immediately after in an impregnation solution. Fourteen days later brains were immersed during $4 \mathrm{~d}$ in a cryoprotectant solution, cut onto $40 \mu \mathrm{m}$ sections, immersed in staining solution for $10 \mathrm{~min}$, rinsed, dehydrated, and mounted for their observation. Images were collected with an Olympus DP70 camera attached to an Olympus BX51 microscope using bright-field illumination. Whole coronal section photomontages were produced in Photoshop by photomerging pictures taken at $4 \times$ magnification. Minimum intensity $Z$-projections from selected dendrites were created in Image (NIH) as described from $z$-series collected at $100 \times$ magnification (Schneider et al., 2012). Observations were performed by a blind observer in the distal dendrites of neurons originated from cortical layer $\mathrm{V}$ within $0.6 \mathrm{~mm}$ from the border of the necrotic core, between 0 and $+0.5 \mathrm{~mm}$ anterior to bregma where the digits of the right forelimb are represented (Tennant et al., 2011) and plastic changes ensue following an ischemic lesion (Zhang et al., 2005; Brown et al., 2007; Li and Murphy, 2008). The number and length of protrusions, as well as the percentage of neurons with dendritic varicosities, were quantified in the distal dendrites of 10 neurons per section, in five cuts per animal, in 12 animals per experimental group ( $n=600$ dendrites) with Image MetaMorph Software in pictures magnified $200 \%$ of their original size.

Immunohistochemistry. Wt cerebral cortical neurons were either left untreated or incubated $60 \mathrm{~min}$ with $10 \mathrm{~nm}$ on uPA. uPAR surface labeling was conducted overnight at $4^{\circ} \mathrm{C}$ using a rabbit anti-uPAR antibody (1: 100 dilution). Twenty-four hours later cells were permeabilized with 20 $\mu \mathrm{g} / \mathrm{ml}$ digitonin and double labeled with either phalloidin or monoclonal antibodies against MAP-2 (1:2500 dilution), or synaptophysin (1: 5000 dilution), or profilin (1:2500 dilution). Cells were photographed using an Olympus BX51 microscope with epifluorescent illumination and an Olympus DP70 digital camera. To determine the percentage of neurons with uPAR-positive extensions 200 neurons from three different cultures were examined. To quantify the percentage of NMDA-induced varicosities that were enriched in UPAR, we counted the number of uPAR-positive and UPAR-negative varicosities in the distal $10 \mu \mathrm{m}$ of 200 dendrites of Wt cerebral cortical neurons following $10 \mathrm{~min}$ of incubation with $10 \mu \mathrm{M}$ NMDA.

Western blot analysis. Extracts of Wt cerebral cortical neurons were incubated with $10 \mathrm{~nm}$ of either uPA or its N-terminal fragment (ATF) during 0-60 min. A subset of neurons was treated with a combination of $10 \mathrm{~nm}$ of uPA and either $5 \mu \mathrm{M}$ of the Rac inhibitor EHT-1864 or $10 \mu \mathrm{M}$ of the ROCK inhibitor Y-27632. Cells were homogenized and protein concentration was quantified using the BCA assay. Fifteen micrograms of protein were loaded per sample, separated by $4-20 \%$ precast linear gradient polyacrylamide gel (Bio-Rad); transferred to a PVDF membrane by semidry transfer system; blocked with $5 \%$ nonfat dry milk in Trisbuffered saline, $\mathrm{pH} 8.0$, with $0.1 \%$ Tween 20 buffer; and immunoblotted with antibodies against cofilin phosphorylated at serine 3 or profilin. Each observation was repeated four times. Densitometry was performed with ImageJ analyzer system (NIH).

Statistical analysis. Values are expressed as percentage or mean $\pm \mathrm{SD}$ when appropriate. Statistical analysis included two-sample $t$ test and one-way ANOVA. $p$ values $<0.05$ were considered significant.

\section{Results}

Effect of cerebral ischemia and hypoxia on neuronal uPA

First we measured the concentration of uPA in the cerebral cortex of Wt mice 30 and $60 \mathrm{~min}$ after the onset of tMCAO (acute 
phase), or 1-24 h after the end of $60 \mathrm{~min}$ of tMCAO (recovery phase). We found that the concentration of uPA in the cerebral cortex does not increase during the acute phase of the ischemic injury $(53 \pm 8$ and $49 \pm 4 \mathrm{pg} / \mathrm{g}$, following 30 and $60 \mathrm{~min}$ of MCAO, respectively, compared with $52.35 \pm 11.47 \mathrm{pg} / \mathrm{g}$ in nonischemic brains; $n=8$ per time point; $p=$ nonsignificant; one-way ANOVA). In contrast, during the recovery phase we detected a marked increase in the concentration of uPA in the ischemic cortex $(77.69 \pm 9,79 \pm$ $10.26,66.4 \pm 13.9$, and $109.2 \pm 15.33 \mathrm{pg} / \mathrm{g}$ at $3,6,12$, and $24 \mathrm{~h}$ after the end of $60 \mathrm{~min}$ of tMCAO, respectively; Fig. $1 A ; n=8$ per condition; compared with brains at 30 and $60 \mathrm{~min}$ of ischemia $p=$ nonsignificant at $1 \mathrm{~h}, 0.001$ at 3 and $6 \mathrm{~h}, 0.03$ at $12 \mathrm{~h}$, and $<0.0001$ at $24 \mathrm{~h}$ of recovery (one-way ANOVA). To study whether this increase in the concentration of uPA during the recovery phase has an effect on the severity of the ischemic injury, we measured the volume of infarcted tissue in $\mathrm{Wt}$ and $\mathrm{uPA}^{-1-}$ mice $24 \mathrm{~h}$ after tMCAO. We found no difference in the volume of the necrotic core between both strains of mice $\left(77 \pm 9 \mathrm{~mm}^{3}\right.$ in $\mathrm{Wt}$ and $82 \pm 11 \mathrm{~mm}^{3}$ in $\mathrm{uPA}^{-1-}$ mice' Fig. $1 B ; n=12$ per strain of mice; $p=$ nonsignificant; two-sample $t$ test).

To study the effect of hypoxia on neuronal uPA, we measured the concentration of uPA in the culture medium of $\mathrm{Wt}$ cerebral cortical neurons following 1, 30, and 55 min of exposure to OGD conditions (acute phase), or 3, 6, and $24 \mathrm{~h}$ after the end of 55 min of OGD (recovery phase). We found that the concentration of uPA in the culture medium does not increase during the acute phase of the hypoxic injury. In contrast, we detected a sharp increase in the concentration of uPA in the culture medium during the recovery phase $(122.39 \pm 16.55,126.20 \pm$ 19.68 , and $181.72 \pm 26.10 \mathrm{pg} / \mathrm{ml}$ at 3,6 , and $24 \mathrm{~h}$ after the end of the acute hypoxic injury, respectively; Fig. $1 C$; each observation was repeated 12 times in cultures from cultures from three different animals; $p<$ 0.0001 one-way ANOVA; at 3, 6, and 24 h compared with 1,30 , and $55 \mathrm{~min}$ of OGD). To determine whether this release of neuronal uPA has an effect on OGD-induced cell death, we used the MTT assay to quantify cell survival in $\mathrm{Wt}$ and $\mathrm{uPA}^{-1-}$ cerebral cortical neurons $24 \mathrm{~h}$ after $55 \mathrm{~min}$ of exposure to OGD conditions. Our results indicate that OGD decreases cell survival in $\mathrm{Wt}$ and $\mathrm{uPA}^{-1-}$ neurons from $100 \pm 1.1$ and $100 \pm 1.3 \%$ in Wt and $\mathrm{uPA}^{-1-}$ control cells, to $55 \pm 6.3$ and $56 \pm 2.2 \%$, respectively (Fig. 1D; each observation was repeated 20 times from cultures from three different animals; ${ }^{\star} p$ and ${ }^{* *} p<0.0001$, two-sample $t$ test; when Wt and $\mathrm{uPA}^{-1-}$ neurons exposed to OGD were compared with cells kept under physiological conditions; $p$ : nonsignificant; two-sample $t$ test; when comparing $\mathrm{Wt}$ and $\mathrm{uPA}^{-1-}$ neurons exposed to OGD conditions).
B
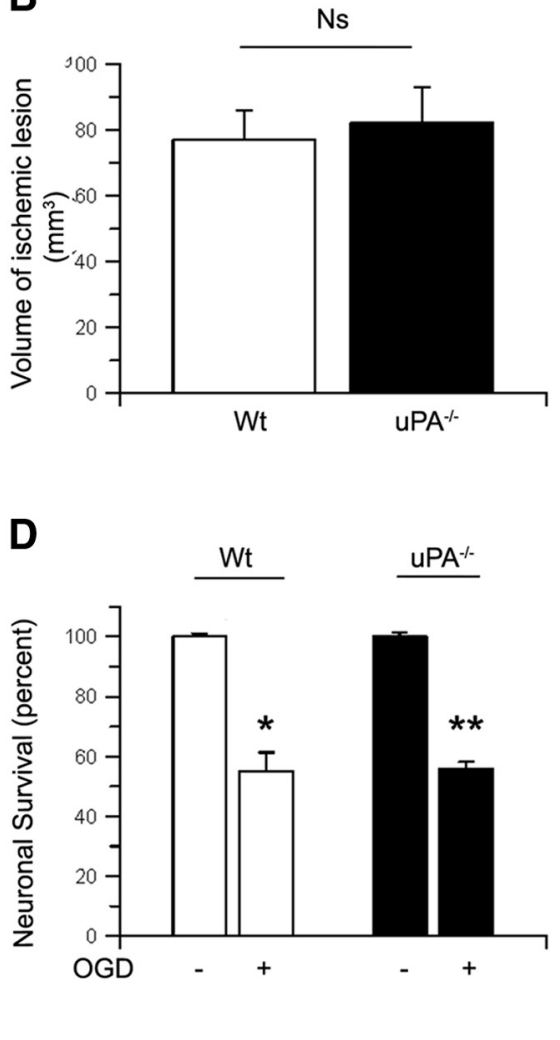

Figure 1. Effect of cerebral ischemia and OGD on neuronal uPA. A, Mean concentration of uPA in the ischemic tissue of Wt mice following 30 and 60 min of tMCA0, or 1-24 h after the end of 60 min of tMCA0 (recovery phase); $n=8$ per time point. ${ }^{*} p=0.001$ min of tMCAO (acute phase), or $1 \mathrm{~h}$ after $60 \mathrm{~min}$ of MCA0. ${ }^{* * *} p=0.03$ compared with uPA concentration in nonischemic brains, and brains after $30 \mathrm{~min}$ or $60 \mathrm{~min}$ of tMCA0. Lines denote SD. Statistical analysis was performed with one-way ANOVA. $\boldsymbol{B}$, Volume of the ischemic lesion in Wt and uPA ${ }^{-1-}$ mice $24 \mathrm{~h}$ after MCAO; $n=12$ per experimental group. Lines denote SD. Statistical analysis was performed with the two-sample $t$ test. C, Mean concentration of uPA in the culture medium of Wt cerebral cortical neurons following 1, 30, and 55 min of exposure to $0 G D$ conditions, or 1, 3, 6, and $24 \mathrm{~h}$ after the end of 55 min of $0 G D$ conditions 0.0001 , and ${ }^{* *} p<0.0001$ compared with uPA concentration in the culture medium of neurons after 1,30 , and 55 min of $0 G D$. p 0.0001 compared with uPA concentration in the culture medium of neurons 3 and $6 \mathrm{~h}$ after the end of 55 min of OGD (black bars) neurons $24 \mathrm{~h}$ after 55 min of exposure to $0 G D$ conditions; $n=20$ per experimental group from neurons from three different animals. ${ }^{*} p<0.0001$ and ${ }^{* *} p<0.0001$ compared with Wt and uPA ${ }^{-1-}$ neurons kept unde normal concentrations of oxygen and glucose (two-sample $t$ test). Lines denote SD. Values are given as a percentage compared with survival in cells maintained under physiological concentrations.

\section{Effect of uPA on neurological recovery following} ischemic stroke

Because our data indicate that cerebral ischemia induces the release of neuronal uPA only during the recovery phase from an ischemic injury, we decided to investigate whether this uPA plays a role in the recovery of neurological function after an ischemic stroke. To test this hypothesis we measured the laterality index (evaluates sensorimotor abnormalities) and the strength in the right forelimb [affected by the ischemic injury to the left primary (M1) and secondary (M2) motor cortices] in Wt, $\mathrm{uPA}^{-1-}$, and $\mathrm{uPAR}^{-1-}$ mice between $6 \mathrm{~h}$ and $7 \mathrm{~d}$ after tMCAO. We found that compared with their own baseline (normalized LI), the LI and forelimb strength were equally affected $6 \mathrm{~h}$ after the end of tMCAO in the three strains of mice. However, while during the first $7 \mathrm{~d}$ after $\mathrm{tMCAO}$ we observed a progressive improvement in both parameters in Wt mice: $1,2,3$, and $7 \mathrm{~d}$ after tMCAO the LI 
A

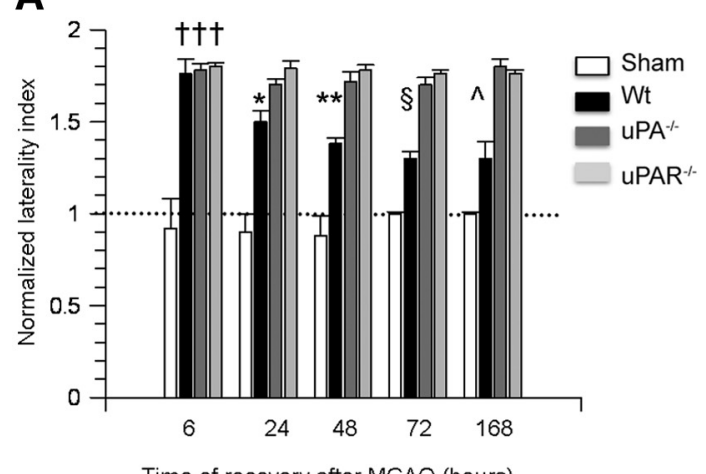

Time of recovery after MCAO (hours)

C

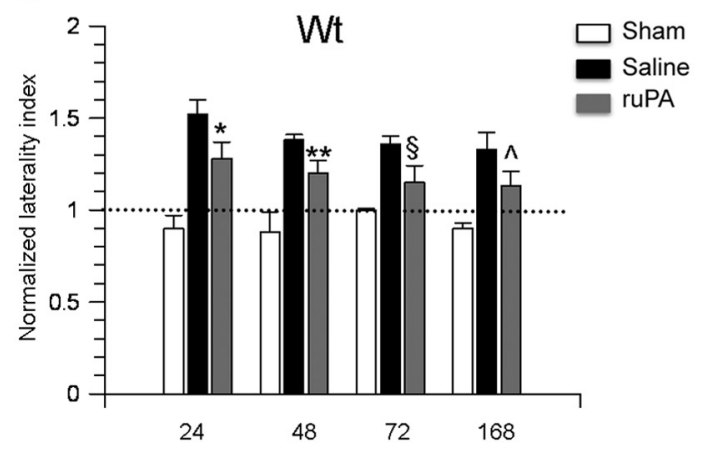

Time of recovery after MCAO (hours)

E

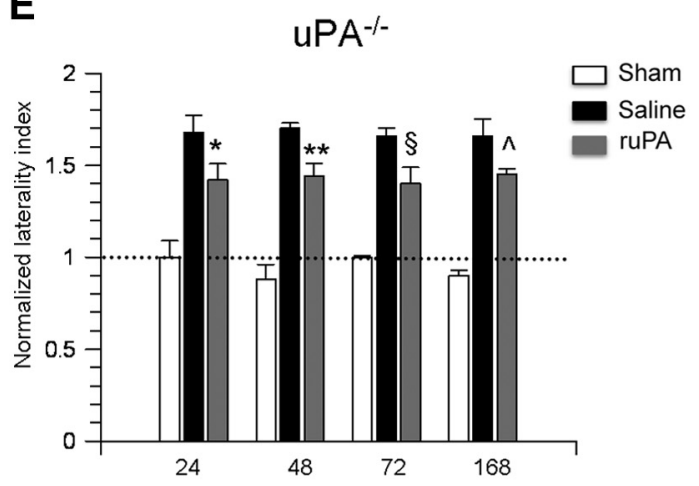

Time of recovery after MCAO (hours)

G

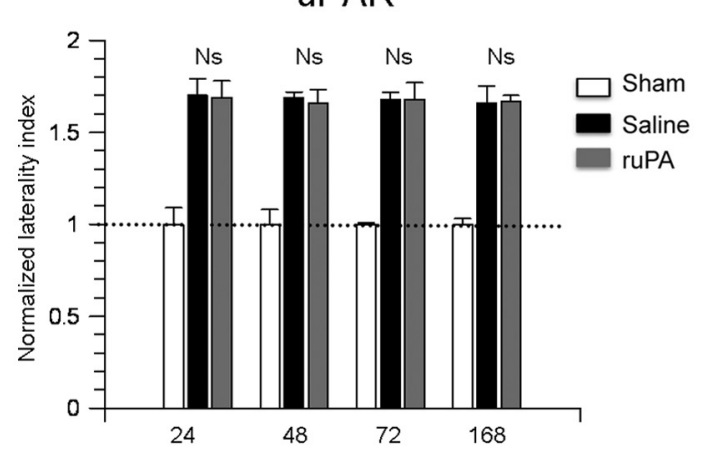

Time of recovery after MCAO (hours)
B

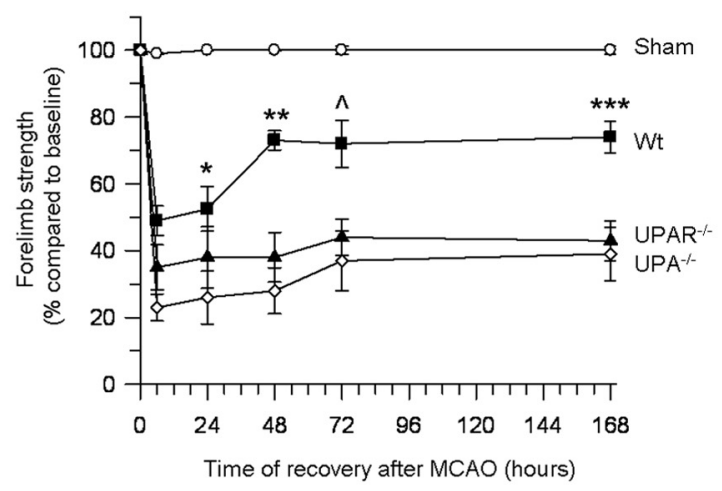

D

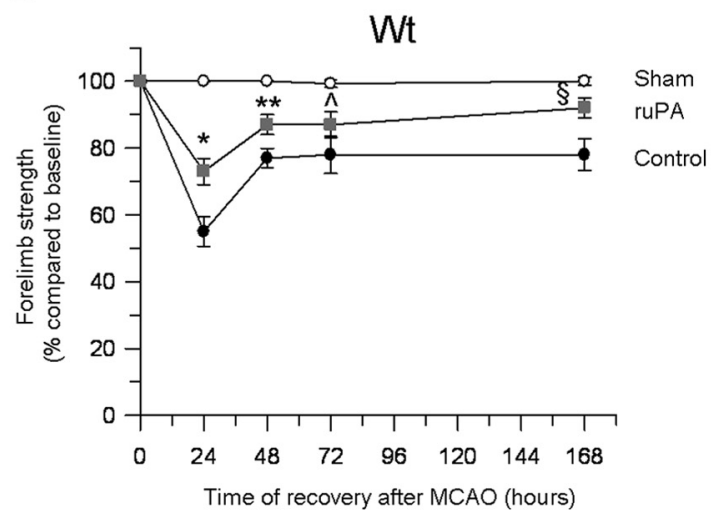

F

$\mathrm{uPA}^{-/-}$

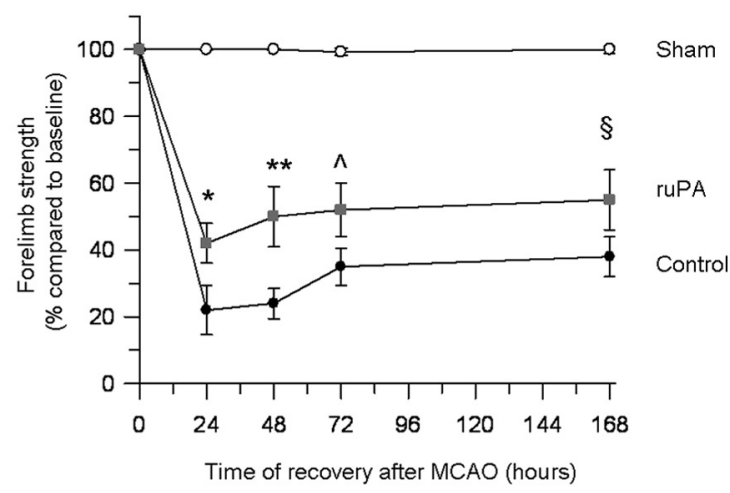

H

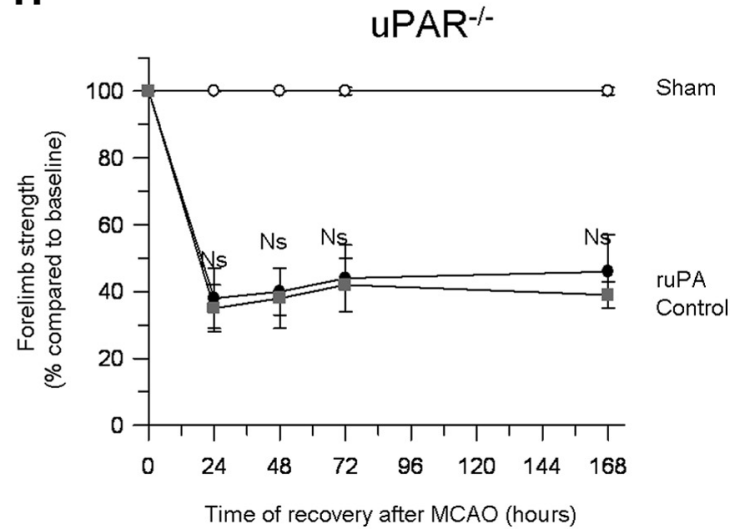

Figure 2. uPA promotes neurological recovery after ischemic stroke. $\boldsymbol{A}, \boldsymbol{B}$, Mean $\mathrm{LI}(\boldsymbol{A})$ and forelimb strength $(\boldsymbol{B})$ in Wt (black bars in $\boldsymbol{A}$ and black squares in $\boldsymbol{B})$, uPA ${ }^{-1-}$ (dark gray bars in $\boldsymbol{A}$ and white diamonds in $\boldsymbol{B}$ ), and uPAR ${ }^{-1-}$ (light gray bars in $\boldsymbol{A}$ and black triangles in $\boldsymbol{B}$ ) mice, between $6 \mathrm{~h}$ and $7 \mathrm{~d}$ fter tMCA0. White bars in $\boldsymbol{A}$ and white circles in $\boldsymbol{B}$ correspond to sham-operated controls. ${ }^{\dagger} p<0.0001$ compared with sham-operated animals. ${ }^{*} p=0.01,{ }^{* *} p<0.0001,{ }^{{ }^{*}} p<0.0001$, and $p<0.0001$ in $A$ compared with Wt mice $6 \mathrm{~h}$ after tMCA0, and with (Figure legend continues.) 
decreased from $1.76 \pm 0.08$ at $6 \mathrm{~h}$ to $1.5 \pm 0.06,1.38 \pm 0.03,1.3 \pm$ 0.04 , and $1.3 \pm 0.09$; forelimb strength improved from $48.96 \pm$ $4.4 \%$ of baseline at $6 \mathrm{~h}$ to $52.5 \pm 6.72,73 \pm 2.89,72 \pm 6.99$, and $74 \pm 4.8 \%$, respectively (Fig. $2 A, B ; n=20$ animals per experimental group).

To further characterize these results, we performed similar observations in $\mathrm{Wt}, \mathrm{uPA}^{-/-}$, and $\mathrm{uPAR}^{-1-}$ mice treated with either $0.1 \mathrm{mg} / \mathrm{kg}$ IA of ruPA or an equivalent volume of saline solution immediately after the end of the ischemic injury (60 min of tMCAO). Our data show that treatment with ruPA improves the $\mathrm{LI}$ and forelimb strength in Wt (Fig. $2 C, D$ ) and uPA ${ }^{-1-}$ (Fig. $2 E, F$ ) mice, but not in uPAR ${ }^{-1-}$ animals (Fig. 2 G, $H ; n=15$ per experimental group). These data indicate that either endogenous uPA or recombinant uPA promotes neurological recovery after tMCAO, and that this effect is mediated by uPAR.

\section{Effect of uPA on the structural reorganization of the peri-infarct cortex}

Because structural reorganization of the cerebral cortex surrounding the necrotic core underlies neurological recovery following an acute ischemic injury (Dijkhuizen et al., 2001), we decided to investigate the effect of uPA on the anatomical remodeling of the peri-infarct cortex. To accomplish this goal we took advantage of two facts. First, in the murine brain the forepaw is represented in the primary (M1) and secondary (M2) cortical areas. Following tMCAO most of the $\mathrm{M} 1$ area is involved by the necrotic core, while $0.1 \mathrm{~mm}$ of the $\mathrm{M} 1$ and $0.5 \mathrm{~mm}$ of the M2 areas are located in the peri-infarct cortex (Fig. $3 A$ ). Thus, the recovery of forelimb strength following tMCAO is mostly driven by structural and functional reorganization the M2 area. This landmark is important because tMCAO produces changes in the fine synaptic structure of neurons located within $0.6 \mathrm{~mm}$ of the border of the necrotic core that are reversible if reperfusion occurs within $60 \mathrm{~min}$ (Li and Murphy, 2008). Second, the diffusion of molecules of water in the brain (MD) and its directionality ( $\mathrm{Fa})$ are determined by the microscopic features of the neural tissue (Le Bihan, 2003). Based on these two facts, we used DTI to quantify the MD and Fa within $0.6 \mathrm{~mm}$ from the border of the necrotic core of Wt and $\mathrm{uPA}^{-1-}$ mice $24 \mathrm{~h}$ after MCAO (Fig. $3 B$ ). We found that compared with a similar area in the nonischemic hemisphere the MD of water within $0.6 \mathrm{~mm}$ from the border of the necrotic core decreased in Wt mice from $0.93 \pm 0.09$ to $0.84 \pm 0.15 \mathrm{~mm}^{2} / \mathrm{s}$ ( $p=$ nonsignificant $)$. In contrast, in $\mathrm{uPA}^{-1-}$ mice we detected an increase from $0.96 \pm 0.06$ to $1.28 \pm 0.18$ $\mathrm{mm}^{2} / \mathrm{s}$ (Fig. 3C; $n=6 ; p=0.001$ ). Furthermore, compared with the nonischemic hemisphere, the Fa increased in Wt mice from $0.76 \pm 0.02$ to $0.83 \pm 0.03(p=0.02)$, and decreased in $\mathrm{uPA}^{-1-}$ animals from $0.75 \pm 0.04$ to $0.59 \pm 0.06(p<0.0001)$. We pos-

\footnotetext{
$\leftarrow$

(Figure legend continued.) $\mathrm{UPA}^{-1-}$ and $\mathrm{PPAR}^{-1-}$ mice at each time point. ${ }^{*} p=0.02,{ }^{* *} p<$ $0.0001, p<0.0001$, and ${ }^{* * *} p<0.0001$ in $B$ compared with sham-operated, and uPA ${ }^{-1-}$ and PPAR $^{-1-}$ mice at each time point; $n=20$ per strain. Lines denote SD. Statistical analysis was performed with one-way ANOVA. $\boldsymbol{C}-\boldsymbol{H}$, Mean $L I(\boldsymbol{C}, \boldsymbol{E}, \boldsymbol{G})$ and forelimb strength $(\boldsymbol{D}, \boldsymbol{F}, \boldsymbol{H})$, in $\mathrm{Wt}(\boldsymbol{C}, \boldsymbol{D}), \mathrm{uPA}^{-1-}(\boldsymbol{E}, \boldsymbol{F})$, and $\mathrm{PPAR}^{-1-}(\boldsymbol{G}, \boldsymbol{H})$ mice, between $24 \mathrm{~h}$ and $7 \mathrm{~d}$ after $\mathrm{MCAO}$. Mice were treated immediately after $\mathrm{MCAO}$ with either intravenous saline solution (black bars in $C$, $\boldsymbol{E}, \boldsymbol{G}$; black circles in $\boldsymbol{D}, \boldsymbol{F}, \boldsymbol{H})$ or with $0.1 / \mathrm{mg} / \mathrm{kg}$ per IA of ruPA (gray bars in $\boldsymbol{C}, \boldsymbol{E}, \boldsymbol{G}$; gray squares in $\boldsymbol{D}, \boldsymbol{F}, \boldsymbol{H}) ; n=15$ observations per time point. Lines denote SD. Compared with mice treated with saline solution at each time point: $C,{ }^{*} p=0.01,{ }^{* *} p=0.04,{ }^{\circledR} p=0.01$, and ${ }^{*} p=0.03$. $D,{ }^{*} p=0.001,{ }^{* *} p=0.02, p=0.04$, and ${ }^{\S} p=0.02 . E^{*}{ }^{*} p=0.01$, ${ }^{* *} p=0.03,{ }^{\S} p=0.02$, and $p=0.001 . \boldsymbol{F},{ }^{*} p=0.001,{ }^{* *} p<0.0001, \hat{p}=0.02$, and ${ }^{\S} p=0.04$. Ns in $\boldsymbol{G}$ and $\boldsymbol{H}$ : nonsignificant compared with saline solution-treated mice $(\boldsymbol{G})$ and controls $(\boldsymbol{H})$ at each time point. Statistical analysis was performed with one-way ANOVA.
}

tulated that these findings were due either to attenuation of vasogenic edema or decrease in the population of neurons in the peri-infarct cortex of $\mathrm{uPA}^{-1-}$ mice. To test this hypothesis we quantified the magnitude of vasogenic edema with Evans blue dye and the number of neurons with an antibody against a neuron-specific nuclear protein $(\mathrm{NeuN})$ in the peri-infarct cortex of $\mathrm{Wt}$ and $\mathrm{uPA}^{-1-}$ mice $24 \mathrm{~h}$ after MCAO. Surprisingly, we found that the severity of vasogenic edema and the population of neurons in this area after tMCAO are similar in both strains of mice (data not shown). Thus, the increase in MD and decrease in Fa observed in $\mathrm{uPA}^{-1-}$ mice could not be explained by a decrease in either vasogenic edema or neuronal population.

Because alterations in the integrity of neurites may also change the MD and Fa of water (Le Bihan, 2003), we used DTI to measure the length of neuronal extensions located within $0.6 \mathrm{~mm}$ of the necrotic border in both groups of mice $24 \mathrm{~h}$ after MCAO. We found that the mean length of 2000 neuronal extensions examined per mouse ( $n=6$ mice per group) was $1.04 \pm 0.086 \mathrm{~mm}^{2}$ in Wt and $0.72 \pm 0.01 \mathrm{~mm}^{2}$ in uPA ${ }^{-1-}$ mice $(p<0.0001$; Fig. $3 E)$. To further characterize this observation, we performed $3 \mathrm{D}$ reconstructions of the distal dendrites of neurons originated in the $\mathrm{V}$ cortical layer within $0.6 \mathrm{~mm}$ of the border of the necrotic core in $\mathrm{Wt}$ and $\mathrm{uPA}^{-1-}$ mice $24 \mathrm{~h}$ after MCAO. We found that whereas the distal dendrites of $\mathrm{Wt}$ mice had many spines and filopodia, those of $\mathrm{uPA}^{-1-}$ animals had fewer protrusions and most of their dendritic shaft was occupied by varicosities (Fig. $3 F$ ). Based on these findings we postulated that the increase in $\mathrm{MD}$ and decrease in $\mathrm{Fa}$ of water observed in $\mathrm{uPA}^{-1-}$ mice was due to impaired recovery of distal neurites and dendritic protrusions in this strain of animals.

To test this hypothesis we quantified the number of dendritic protrusions in the peri-infarct cortex of $\mathrm{Wt}$ and $\mathrm{uPA}^{-1-}$ mice 6 , 24 , and $168 \mathrm{~h}$ (7 d) after tMCAO. We performed our observations in the distal $10 \mu \mathrm{m}$ of dendrites from Golgi-stained pyramidal neurons from cortical layer $\mathrm{V}$, located within $0.6 \mathrm{~mm}$ from the border of the necrotic core (Fig. $4 A, B$ ), where the forepaw is represented (Tennant et al., 2011) and reversible changes in the synaptic structure following tMCAO have been previously reported (Li and Murphy, 2008). Our data indicate that $6 \mathrm{~h}$ after tMCAO most of the dendritic spines in both Wt and $\mathrm{uPA}^{-/-}$ mice are replaced by varicosities (Fig. $4 c, d$ ). More specifically, the number of dendritic protrusions per $10 \mu \mathrm{m}$ decreased in $\mathrm{Wt}$ and $\mathrm{uPA}^{-1-}$ mice from $11 \pm 1(\mathrm{Wt})$ and $11 \pm 3\left(\mathrm{uPA}^{-1-}\right)$ under nonischemic conditions to $2 \pm 0.2(\mathrm{Wt})$ and $2 \pm 0.8\left(\mathrm{uPA}^{-1-}\right.$; Fig. $4 D$ ). At $24 \mathrm{~h} \mathrm{Wt}$ neurons exhibited a significant increase in the number $(7 \pm 1.9, p<0.0001$, one-way ANOVA; $n=12$ per group; Fig. $4 D)$, and length $(3.4 \pm 1.1 \mu \mathrm{m}$ compared with $1.1 \pm$ $0.08 \mu \mathrm{m}$ in nonischemic brains; Fig. $4 F$ ) of dendritic protrusions. In contrast, $\mathrm{uPA}^{-1-}$ mice only had varicosities and very small protrusions. Remarkably, although $7 \mathrm{~d}$ later the number of dendritic protrusions in $\mathrm{Wt}$ mice remained unchanged, their length decreased to baseline levels (Fig. 4C,F)

To determine whether the effect of uPA is mediated by its receptor we performed similar observations in $\mathrm{UPAR}^{-1-}$ and Plau GFDhu/GFDhu mice ( $n=12$ per group). We found that these animals harbor the same number of dendritic protrusions under nonischemic conditions than Wt mice, and exhibit a quantitatively similar decrease in its number $6 \mathrm{~h}$ after tMCAO (Fig. 4D). However, as observed with $\mathrm{uPA}^{-1-}$ mice, we failed to detect dendritic spine recovery at $24 \mathrm{~h}$ or $168 \mathrm{~h}$ after tMCAO in either $\mathrm{uPAR}^{-/-}$or Plau GFDhu/GFDhu animals, indicating that the effect of endogenous uPA on dendritic spine recovery is mediated by uPAR (Fig. 4D,E). 
A

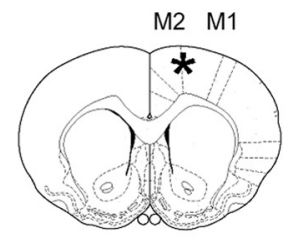

M2 M1

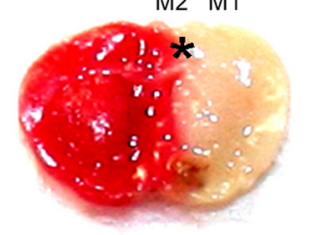

C

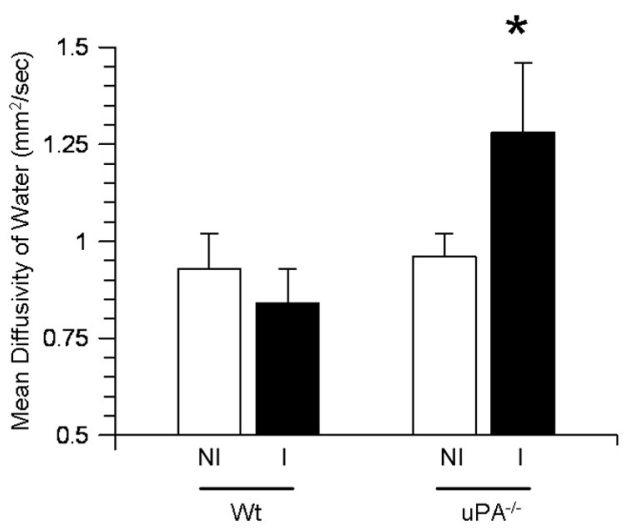

E

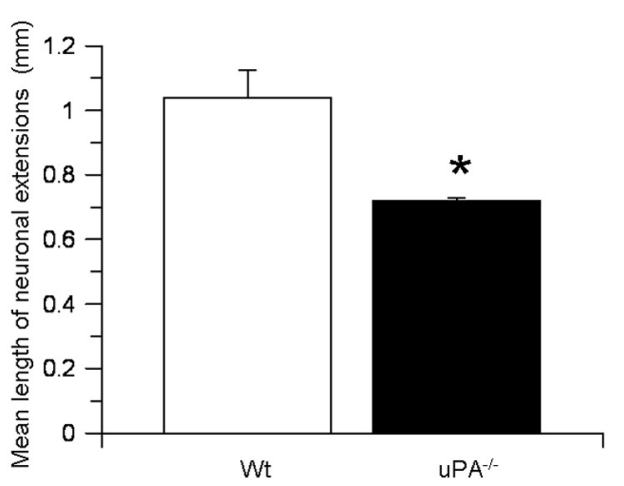

B
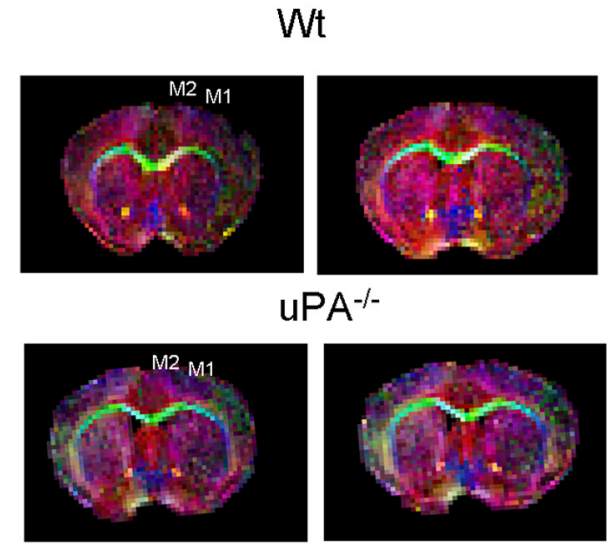

D

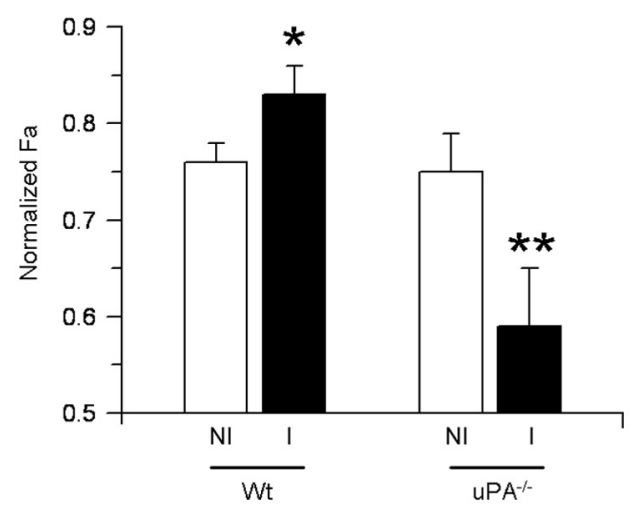

$\mathbf{F}$

Control

Wt
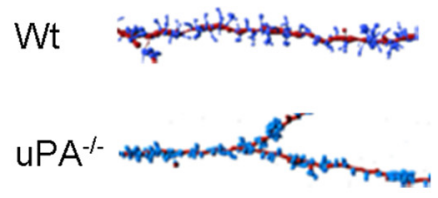

$24 \mathrm{~h}$ after MCAO

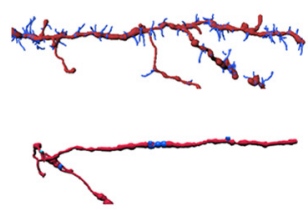

Figure 3. Effect of uPA deficiency on the anatomical structure of the peri-infarct cortex. A, Diagram (top) and representative TTC staining (bottom) of a coronal cut through bregma $+0.5024 \mathrm{~h}$ after MCAO. The asterisk denotes the area of the brain where quantifications and observations presented in $\boldsymbol{E}$ and $\boldsymbol{F}$ were performed. M1 and M2 denote primary and secondary motor cortices, respectively. $\boldsymbol{B}$, Representative photographs of combined DTIs and Fa maps in Wt and uPA ${ }^{-1-}$ mice $24 \mathrm{~h}$ after MCAO. Colors represent fiber orientation: red, mediolateral; green, dorsoventral; blue, rostrocaudal. $\boldsymbol{C}, \boldsymbol{D}, \mathrm{MD}$ of water $(\boldsymbol{C})$ and $\mathrm{Fa}(\boldsymbol{D})$ in the area denoted by the asterisk in $\boldsymbol{A}$ and $\boldsymbol{B}$ in the nonischemic (NI; white bars) and ischemic $\left(\mathrm{l}\right.$; black bars) cortex of Wt and uPA ${ }^{-1-}$ mice $24 \mathrm{~h}$ after MCAO. $C,{ }^{*} p=0.001$ compared with the nonischemic hemisphere in $\mathrm{PPA}^{-1-}$ mice. $\boldsymbol{D},{ }^{*} p=0.02$ compared with the nonischemic hemisphere in Wt mice. ${ }^{* *} p<0.0001$ compared with the nonischemic hemisphere in uPA ${ }^{-1-}$ mice; $n=6$ mice per experimental group. Lines denote SD. Statistical analysis was performed with two-sample $t$ test. $E$, Mean length of distal neurites located within $0.6 \mathrm{~mm}$ of the border of the necrotic core in Wt (white bar) and $\mathrm{PPA}^{-1-}$ (black bar) mice $24 \mathrm{~h}$ after MCAO; $n=6$ mice per experimental group. Bars represent mean values obtained from the analysis of 2000 extensions per mouse; ${ }^{*} p<0.0001$. Lines indicate SD. $\boldsymbol{F}$, Representative micrographs of a tridimensional reconstruction of Dil-stained distal dendrites from neurons originated in cortical layer V from Wt and uPA ${ }^{-1-}$ mice either under nonischemic conditions (controls) or $24 \mathrm{~h}$ after $\mathrm{MMCAO}$. Red is the dendritic shaft and blue corresponds to dendritic protrusions.

\section{uPA promotes dendritic spine recovery following an} excitotoxic injury

Cerebral ischemia induces the excitotoxic release of neurotransmitters from the presynaptic bouton (Benveniste et al., 1984). Because dendritic spines are the postsynaptic terminal of most of the excitatory synapses in the CNS (Hering and Sheng, 2001), and since excitotoxicity is a basic pathophysiologic mechanism of neuronal injury in the ischemic brain, we postulated that the binding of uPA to its receptor UPAR promotes the recovery of dendritic spines following an excitotoxic injury. To test this hypothesis, first we studied the expression of uPAR in cerebral cortical neurons. We found that uPAR is abundantly expressed in the cell body and extensions of $58.1 \pm 10.8 \%$ of 200 neurons examined (Fig. 5A). To investigate whether these extensions corre- 
A

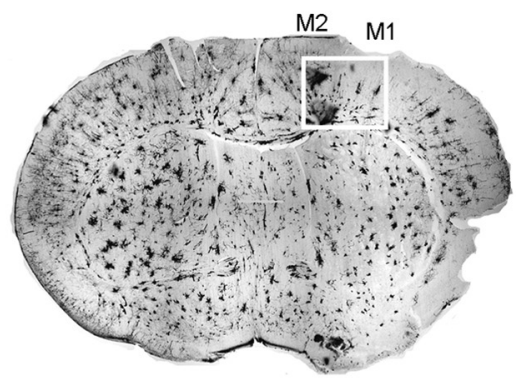

C

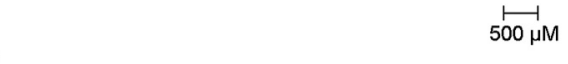

C

Wt

$\mathrm{uPA}^{-1-}$

NI

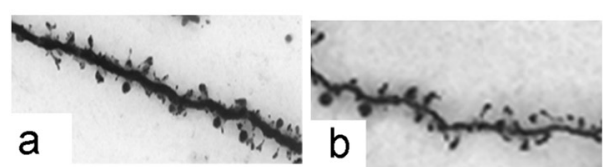

$6 h$
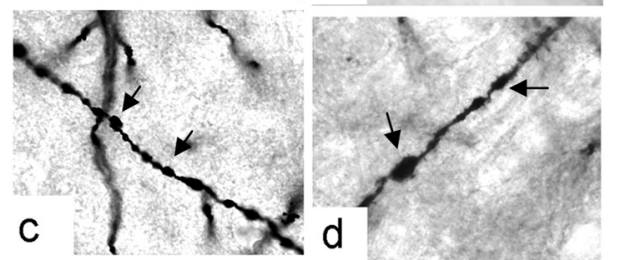

24h
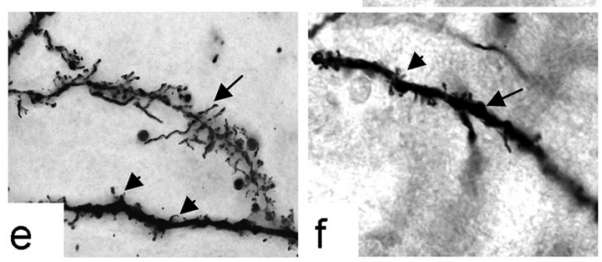

$7 d$

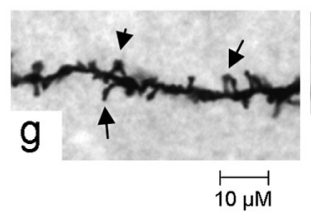

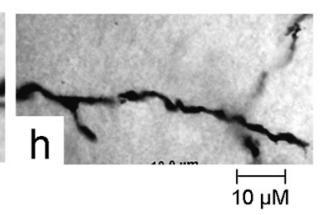

B
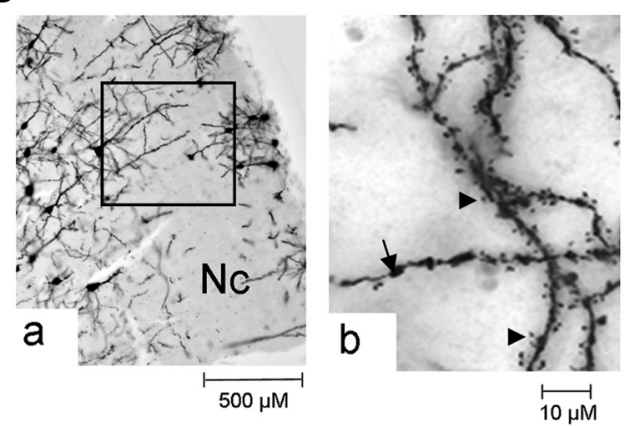

D

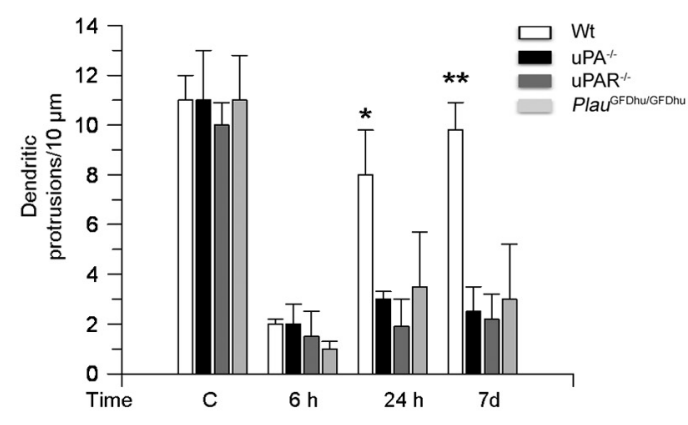

E

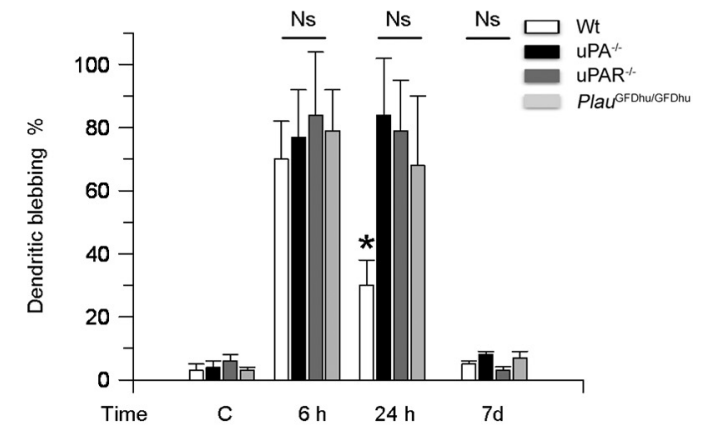

F

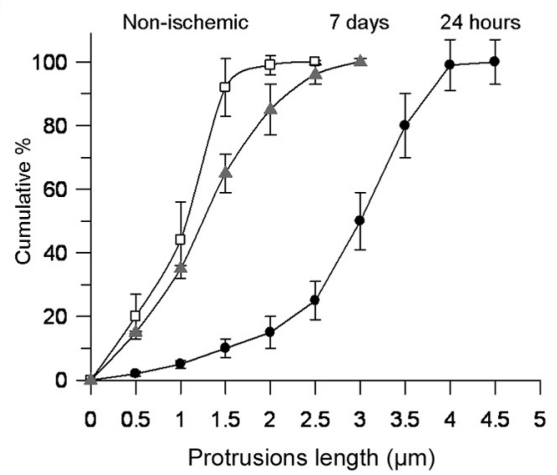

Figure 4. UPA mediates dendritic spine recovery in the peri-infarct cortex. A, Representative micrograph of a Golgi-stained coronal section at bregma: $+0.5 \mathrm{~mm}$ from a Wt brain $24 \mathrm{~h}$ after $t M C A 0$. $\mathrm{M} 1$ and $\mathrm{M} 2$ denote primary and secondary motor cortices, respectively. The square denotes the interface between the necrotic core $(\mathrm{Nc}$ ) and peri-infarct cortex where observations presented in $\boldsymbol{C} \boldsymbol{- F}$ were performed. Magnification: $4 \times$. $\boldsymbol{B}$, Representative micrographs taken from the interphase between the Nc and peri-infarct cortex $(\boldsymbol{a})$. $\boldsymbol{b}$, Shows the area located within $0.6 \mathrm{~mm}$ from the border of the Nc where dendritic spines (arrowheads) are intermixed with dendritic varicosities (arrows). Magnification: $40 \times$ in $\boldsymbol{a}$, and 100 $\times$ in $\boldsymbol{b}$. C, Representative micrographs of Golgi-stained dendrites located within $0.6 \mathrm{~mm}$ from the border of the Nc from Wt and $\mathrm{PPA}^{-1-}$ mice 6, 24, and $168 \mathrm{~h}$ (7 d) after tMCAO. NI, nonischemic brains (controls). Arrows in c and d denote dendritic varicosities. Arrows and arrowheads in $\boldsymbol{e}$ denote filopodia and varicosities, respectively. Arrows and arrowheads in $\boldsymbol{f}$ denote dendritic varicosities and small protrusions, respectively. Arrowhead and arrows in $\boldsymbol{g}$ denote dendritic spines and long thin protrusions, respectively. $\boldsymbol{D}, \boldsymbol{E}$, Mean number of dendritic protrusions per $10 \mu \mathrm{m}(\boldsymbol{D})$ and percentage of neurons with dendritic blebbing $(\boldsymbol{E}) 0.6 \mathrm{~mm}$ from the border of the

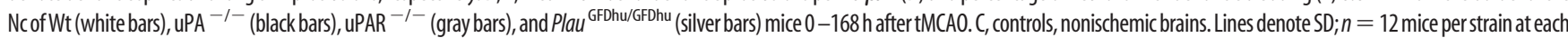
time point. $\boldsymbol{D},{ }^{*} p<0.0001$ and ${ }^{* *} p<0.0001$ compared with Wt at 6 h and $\mathrm{UPA}^{-1-}$, $\mathrm{UPAR}^{-1-}$, and Plau ${ }^{\text {GFDhu/GDhu }}$ brains 6, 24 , and $168 \mathrm{~h}$ after tMCA0.E, ${ }^{*} p<0.0001$ compared with Wt at $6 \mathrm{~h}$ and with $\mathrm{UPA}^{-1-}, \mathrm{uPAR}^{-1-}$, and Plau ${ }^{\text {GFDhu/GDhu }}$ brains and 6, 24, and $168 \mathrm{~h}$ after tMCAO. Statistical analysis was performed with two-way ANOVA test. F, Cumulative frequency plot of spine length in the distal $10 \mu \mathrm{M}$ of 600 dendrites examined from Wt mice either under nonischemic conditions (white squares) or 24 and $168 \mathrm{~h}$ after $60 \mathrm{~min}$ of tMCAO (black circles and gray triangles, respectively). 
A

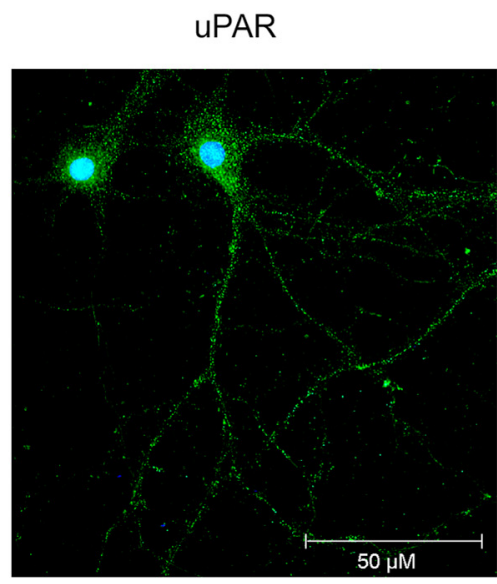

D

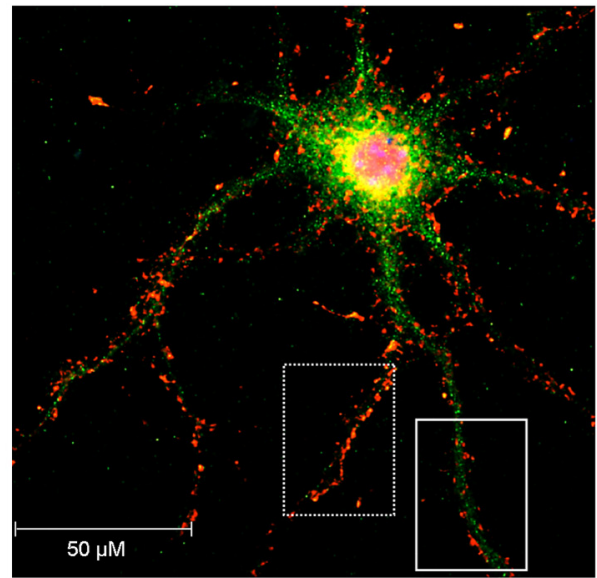

B MAP-2 UPAR Merged
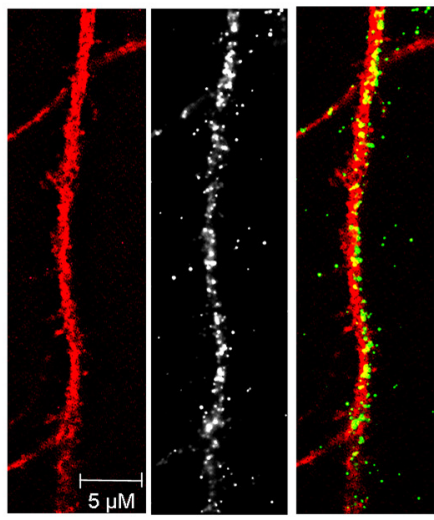

Syn

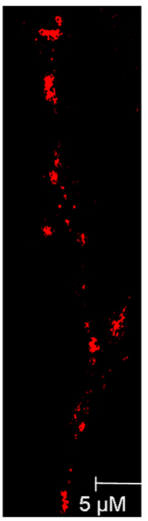
UPAR Merged
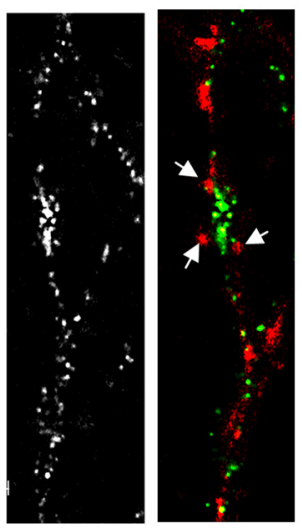

E

Phalloidin

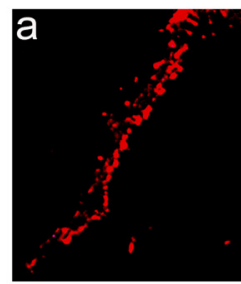

UPAR

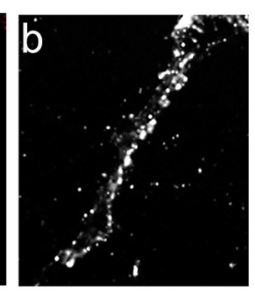

Merged
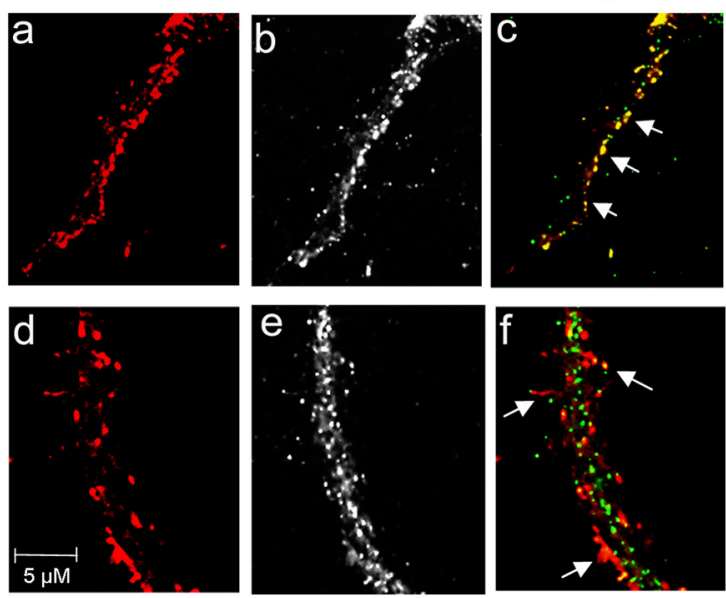

Figure 5. uPAR expression in cerebral cortical neurons. $A$, Representative micrograph of uPAR expression in cerebral cortical neurons. Green, uPAR; blue, DAPI. Magnification: 20×. $B, C$, Representative micrographs of wild-type cerebral cortical neurons stained with antibodies against uPAR (white and green in $\boldsymbol{B}$ and $\boldsymbol{C}$ ) and MAP-2 (red in $\boldsymbol{B}$ ) or synaptophysin (red in $\boldsymbol{C}$ ). Arrows in $\boldsymbol{C}$ denote examples where presynaptic synaptophysin-containing vesicles face uPAR-expressing postsynaptic dendrites. Magnification: $60 \times$. D, E, Representative micrograph of uPAR immunostaining (green in $\boldsymbol{D}$ and white and green in $\boldsymbol{E}$ ) and phalloidin (red in $\boldsymbol{D}$ and $\boldsymbol{E}$ ) in a distal dendrite of a Wt cerebral cortical neuron. The dashed and continuous squares correspond to the areas magnified in $\boldsymbol{E} \boldsymbol{a}-\boldsymbol{c}$ and $\boldsymbol{d}-\boldsymbol{f}$, respectively. Arrows in c indicate colocalization of uPAR and phalloidin. Arrows in $\boldsymbol{f}$ denote an example where uPAR is localized in the tip of dendritic protrusions. Magnification: $20 \times$ in $D$ and $60 \times$ in $E$.

spond to axons or dendrites, we performed a costaining with antibodies against MAP-2 (detect dendrites) and uPAR. Our data show that most of the uPAR-positive extensions are dendrites (Fig. 5B), and further staining with synaptophysin (present in the presynaptic compartment of the axon) corroborated this localization (Fig. 5C, arrows; indicate examples where presynaptic synaptophysin-positive vesicles face uPAR-positive dendrites). Interestingly, we also detected uPAR in the axons of several neurons. Then we performed a costaining with anti-uPAR antibodies and phalloidin (spines and filopodium are rich in F-actin) to characterize the relation between $\mathrm{UPAR}$ and dendritic protrusions. We found that although most of uPAR is diffusely expressed throughout the dendrite, some is located in the base and head of spines and filopodia (Fig. $5 D, E$ ).

To test the effect of $\mathrm{UPA} / \mathrm{uPAR}$ on dendritic spine recovery we used an in vitro model of excitotoxic injury in which 10 min of exposure to a sublethal concentration of NMDA induces the disappearance of dendritic spines and formation of dendritic varicosities (Fig. 6A, a,b). However, $3 \mathrm{~h}$ after withdrawing the excitotoxic injury filopodia and dendritic spines re-emerge from these varicosities (recovery phase; Fig. 6A,c). First we investi- gated the effect of the excitotoxic injury on the expression of uPAR. Our immunohistochemical studies revealed that in contrast with the diffuse distribution of uPAR throughout the dendrite of unchallenged neurons (Fig. 5), the excitotoxic injury induces the clustering of uPAR in $68.4 \pm 14 \%$ of the dendritic varicosities of uPAR-expressing neurons (Fig. 6B, C). Remarkably, uPAR was present not only in these areas of focal swelling, but also in dendritic spines and filopodia re-emerging from these varicosities during the recovery phase (Fig. $6 D$, arrows). Based on these data we postulated that the binding of uPA to uPAR induces the re-emergence of dendritic spines and filopodia from dendritic varicosities during the recovery phase of the excitotoxic injury.

To test this hypothesis we quantified the number of dendritic protrusions in the distal dendrites of $\mathrm{Wt}, \mathrm{uPA}^{-/-}$, and $\mathrm{uPAR}^{-/-}$ cerebral cortical neurons $10 \mathrm{~min}$ after exposure to $10 \mu \mathrm{M}$ NMDA and $3 \mathrm{~h}$ after withdrawal of the excitotoxic injury. A subgroup of neurons was treated with $10 \mathrm{nM}$ uPA immediately after the end of NMDA exposure. Our data indicate that $10 \mathrm{~min}$ of NMDA treatment decreases the number of dendritic protrusions per $10 \mu \mathrm{m}$ in $\mathrm{Wt}, \mathrm{uPA}^{-1-}$, and $\mathrm{uPAR}^{-1-}$ neurons from $6.14 \pm 0.77,5.9 \pm$ 0.32 , and $6 \pm 0.45$ to $0.2 \pm 0.17,0.1 \pm 0.01$, and $0.2 \pm 0.1$, 
A

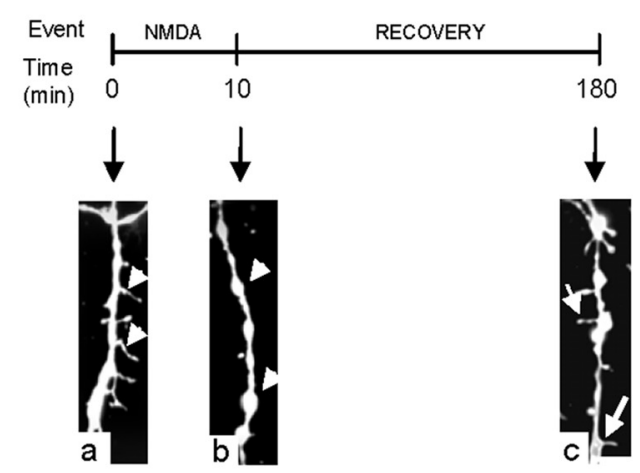

C

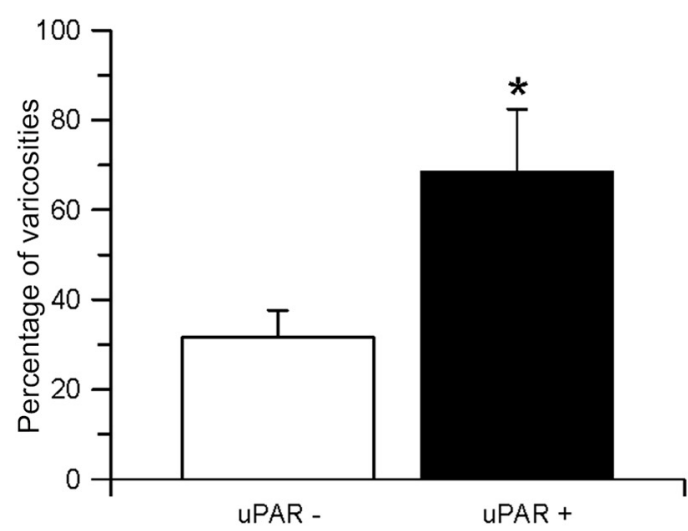

E

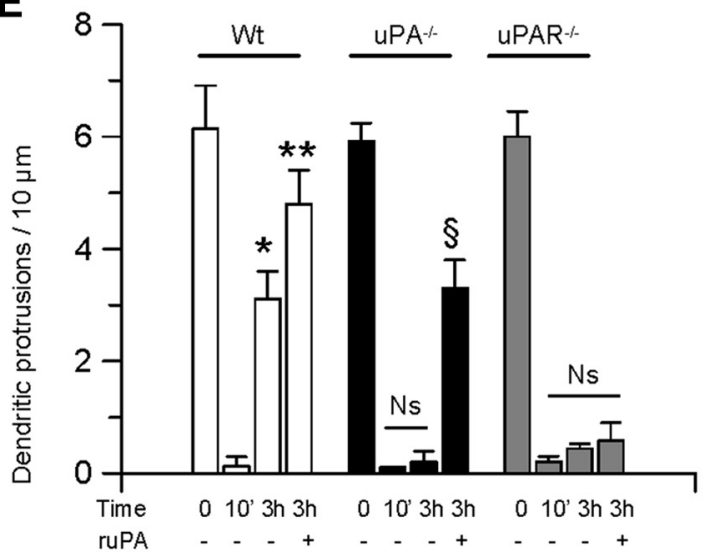

B
MAP-2

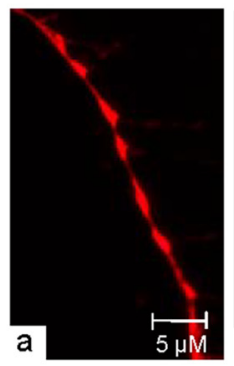

UPAR

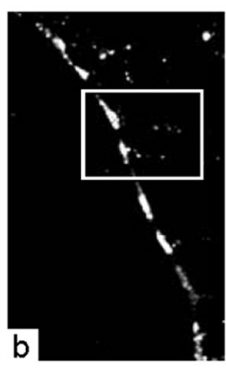

Merged

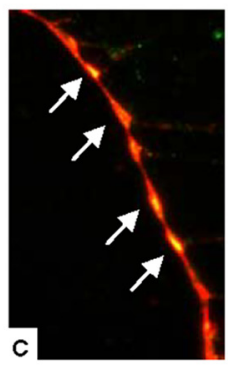

D
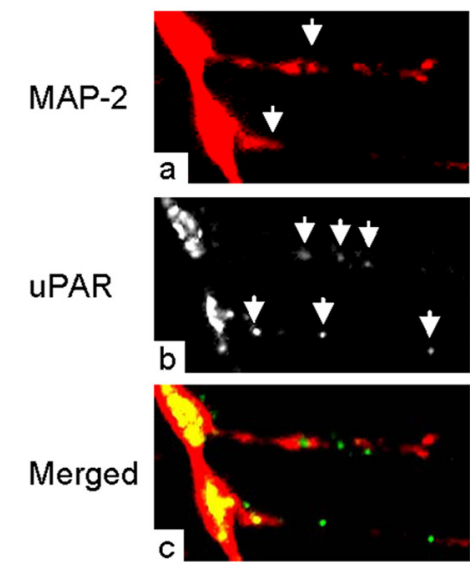

Figure 6. UPA promotes dendritic protrusion recovery following an excitotoxic injury. $A$, Diagram of the experimental paradigm used to study the effect of uPA on dendritic spine recovery following an excitotoxic injury. $\boldsymbol{a}-\boldsymbol{c}$, Correspond to examples of Dil-stained distal dendrites either at baseline $(\boldsymbol{a})$, or 10 min after exposure to NMDA (b; acute injury), or 180 min after withdrawing NMDA ( $\boldsymbol{c}$; recovery). Arrowheads denote dendritic spines in $\boldsymbol{a}$ and varicosities in $\boldsymbol{b}$. Arrows in $\boldsymbol{c}$ show dendritic spines and filopodia re-emerging from varicosities. $\boldsymbol{B}$, Representative micrograph of MAP-2 (red) and uPAR (white in $\boldsymbol{b}$ and yellow in c) staining in the distal dendrite of a Wt neuron $3 \mathrm{~h}$ after 10 min of incubation with NMDA. Arrows in $\boldsymbol{c}$ denote uPAR clustered within dendritic varicosities. Magnification: $40 \times$.C, Mean percentage of uPAR-negative (white bar) and uPAR-positive (black bar) varicosities in the distal $10 \mu \mathrm{m}$ of Wt dendrites following 10 min of treatment with NMDA ( $n=200$ neurons from three different cultures; $p<0.001$; two-sample $t$ test). Lines denote SD. $\boldsymbol{D}$, Magnification of the area denoted by the square in $\boldsymbol{B}$. Arrows denote uPAR in filopodia re-emerging from a uPAR-enriched varicosity. Red is MAP-2, white $(\boldsymbol{b})$ and green $(\boldsymbol{c})$ are uPAR. Magnification: $100 \times$. $\boldsymbol{E}$, Mean number of dendritic protrusions per10 $\mu \mathrm{m}$ in the distal dendrites of $\mathrm{Wt}$ (white bars), $\mathrm{uPA}^{-1-}$ (black bars), and uPAR ${ }^{-/-}$(gray bars) cerebral cortical neurons either at baseline (time 0 ), or immediately after 10 min of incubation with NMDA, or $3 \mathrm{~h}$ after recovery from 10 min of incubation with NMDA. A subset of Wt, $\mathrm{UPA}^{-1-}$, and $\mathrm{uPAR}^{-1-}$ neurons were treated with $10 \mathrm{~nm}$ uPA immediately after the end of the excitotoxic injury (ruPA). ${ }^{*} p<0.0001$ compared with Wt neurons immediately after NMDA exposure; ${ }^{* *} p=0.001$ compared with untreated Wt neurons $3 \mathrm{~h}$ after NMDA exposure; ${ }^{\S} p<0.0001$ compared with uPA ${ }^{-1-}$ neurons either immediately after exposure to NMDA or $3 \mathrm{~h}$ after NMDA exposure but no treatment with ruPA; $n=60$ per time point. Each observation was repeated in cultures from three different animals. Statistical analysis was performed with one-way ANOVA.

respectively. However, $3 \mathrm{~h}$ after the withdrawal of the excitotoxic injury (recovery phase) the number of dendritic protrusions increased to $3.1 \pm 0.5$ in Wt neurons $(p<0.0001)$ and remained unchanged in $\mathrm{uPA}^{-1-}$ and $\mathrm{uPAR}^{-1-}$ cells. Importantly, treat- ment with ruPA after the end of the excitotoxic injury increased the number of protrusions in $\mathrm{Wt}$ and $\mathrm{uPA}^{-1-}$ dendrites to $4.8 \pm$ 0.6 and $3.3 \pm 0.5$, respectively $(p<0.0001)$, but did not have an effect on $\mathrm{uPAR}^{-1-}$ neurons (Fig. $6 E$ ). 
A
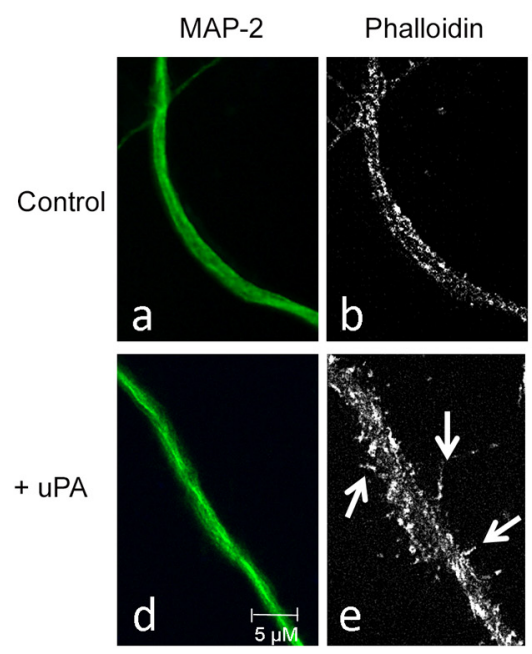

C
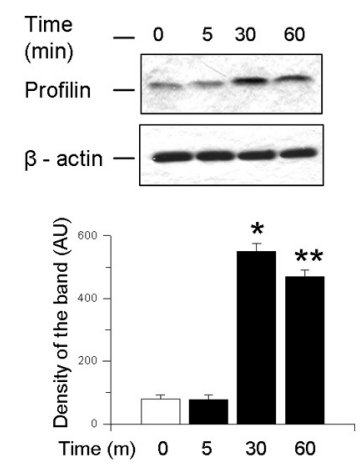

$\mathbf{F}$

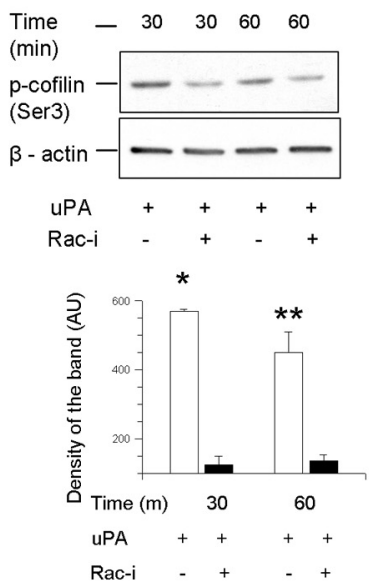

B
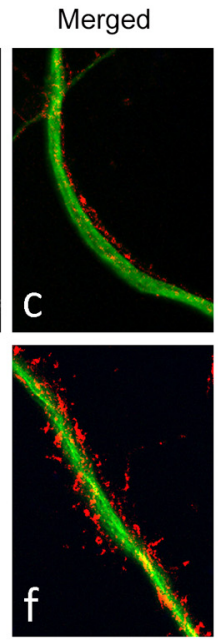

MAP-2
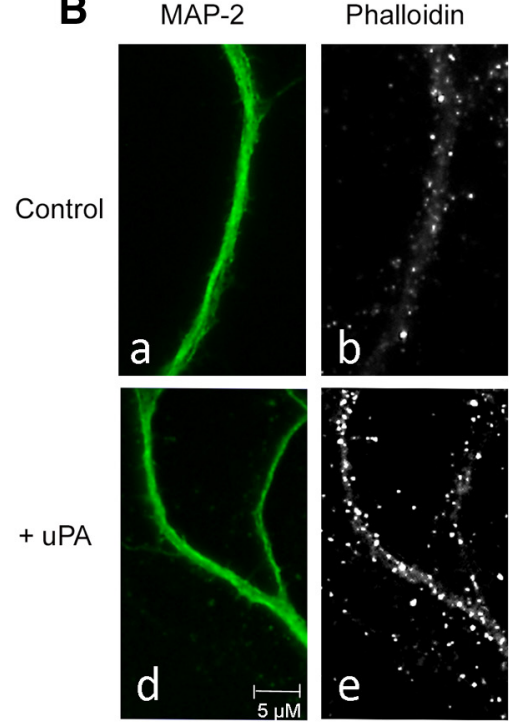

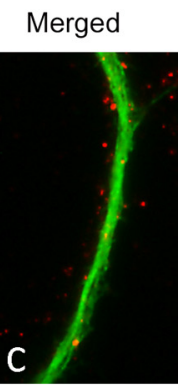

D

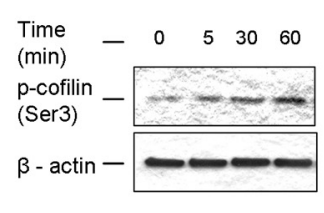

E

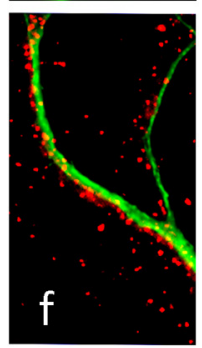

E $\quad \underset{(m i m)}{(m)}$
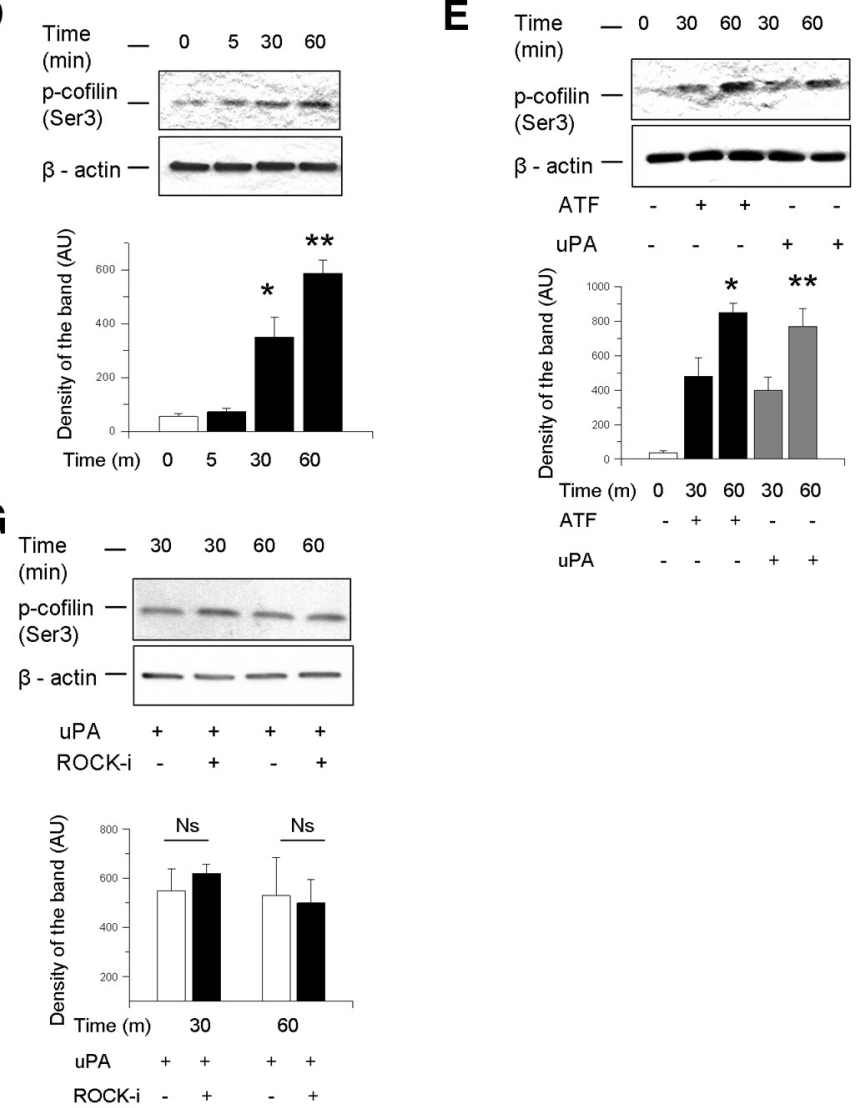

Figure 7. uPA induces cytoskeletal reorganization in dendritic protrusions. A, Representative micrograph of MAP-2 (green) and phalloidin (white and red) staining in a dendrite of a Wt cerebral cortical neuron incubated $60 \mathrm{~min}$ with either $10 \mathrm{~nm}$ of uPA (+ uPA) or vehicle (control). Arrows in e denote phalloidin-positive dendritic filopodia. Magnification: $60 \times$. B, Representative micrograph of MAP-2 (green) and profilin (white and red) staining in a Wt cerebral cortical neuron incubated 60 min with either $10 \mathrm{~nm}$ of uPA (+ uPA) or vehicle (control). Note that uPA treatment induces the expression of profilin not only in the dendrite but also in the axon. Magnification: $60 \times . C-G$, Representative Western bot analysis and quantification of the mean density of the band of profilin $(\boldsymbol{C})$ and cofilin $(\boldsymbol{D}, E)$ phosphorylated at serine 3 (p-coflin) in Wtcerebral cortical neuronsincubated 0 - 60 min with $10 \mathrm{nmuPA}(C, D)$, or 10 nm of uPA's N-terminalfragment (ATF; $E$ ), or a combination of uPA and either $5 \mu$ m of the Racinhibitor EHT-1864 (Rac-l; $F$ ), or $10 \mu \mathrm{m}$ of the ROCKinhibitor Y-27632 (ROCK-I; G).C, D, ${ }^{*} p<0.0001$ and ${ }^{* *} p<0.0001$ compared with cells treated $0-5$ min with uPA. $E_{,}{ }^{*} p<0.0001$ and ${ }^{* *} p<0.0001$ compared with cells either left untreated or incubated 30 min with UPA or ATF. $F^{*} p<0.0001$ and ${ }^{* *} p<0.0001$ compared with cells treated with uPA in the presence of the Racinhibitor EHT-1864. Statistical analysis was performed with one-way ANOVA.

uPA induces the reorganization of the actin cytoskeleton in dendritic protrusions

Dendritic spines have globular (G) and filamentous (F) actin. Because the emergence of filopodia and spines is driven by the formation and stabilization of F-actin (Hotulainen and Hoogen- raad, 2010), we decided to study the expression of F-actin in dendrites of neurons incubated with $10 \mathrm{~nm}$ uPA or with an equivalent volume of vehicle (control). Our data indicate that compared with vehicle-treated neurons (Fig. $7 A, a-c$ ), $60 \mathrm{~min}$ of incubation with uPA $(+\mathrm{uPA})$ induces a marked increase in the 
expression of F-actin in dendritic spines and filopodia (Fig. $7 A, d-f)$. Because the formation of filopodia involves the addition of G-actin monomers to the "barbed" end of the F-actin filament, then we decided to study the expression of profilin (promotes the polymerization of actin at the barbed end of the actin filament) following 0-60 min of incubation with $10 \mathrm{nM}$ uPA. Our data indicate that treatment with uPA induces the expression of profilin in dendritic protrusions (Fig. $7 B, C$ ). Since the stabilization of the filopodia requires inhibition of depolymerization at the "pointed" end of the actin filament, we used a similar experimental setting to investigate the expression of cofilin inactivated by phosphorylation at serine 3 (p-cofilin; active cofilin promotes severing and depolymerization of actin at the pointed end). We found that uPA induces the phosphorylation of cofilin in cerebral cortical neurons (Fig. $7 D$ ), and that this effect does not require uPA's proteolytic properties because it is also observed following incubation with $10 \mathrm{~nm}$ of the $\mathrm{N}$-terminal fragment (ATF) of UPA, which contains the growth factor-like and kringle, but not the proteolytic domain (Fig. 7E). Because the Rho family of GTPases plays a central role in the morphogenesis of dendritic spines by modulating the organization of the actin cytoskeleton (Murakoshi et al., 2011), we decided to study the expression of $\mathrm{p}$-cofilin in cerebral cortical neurons incubated with $\mathrm{UPA}$, alone or in combination with either $10 \mu \mathrm{M}$ of an inhibitor of ROCK-I and ROCK-II (Y-27632), the downstream kinase that mediates the effects of RhoA (Heasman and Ridley, 2008), or $5 \mu \mathrm{M}$ of a Rac inhibitor (EHT-1864). Our data show that Rac but not RhoA mediates the effect of uPA on the phosphorylation of cofilin (Fig. $7 F, G)$.

\section{Discussion}

The two main plasminogen activators, tissue-type and urokinasetype plasminogen activators ( $\mathrm{PA}$ and $\mathrm{uPA}$ ), are expressed in the CNS (Del Bigio et al., 1999). However, while it is known that tPA plays a central role in the regulation of neuronal activity during physiological and pathological conditions (Samson and Medcalf, 2006), the function of uPA in the CNS is less clear. For example, whereas some studies have reported that uPA protects neurons from excitotoxin-induced (Cho et al., 2012) and amyloid- $\beta$ induced neuronal death (Tucker et al., 2000), others indicate that uPA either is neurotoxic (Thornton et al., 2008) or does not have an effect on neuronal survival (Nagai et al., 1999).

In previous studies we demonstrated that cerebral ischemia in vivo and hypoxia in vitro induce the rapid release of tPA from cerebral cortical neurons (Yepes et al., 2000; Echeverry et al., 2010; Wu et al., 2012), and that this tPA has a neuroprotective effect in the ischemic brain and in neurons exposed to OGD conditions (Wu et al., 2012; 2013a,b). In contrast, in the studies presented here we report that OGD and cerebral ischemia induce the release of uPA from cerebral cortical neurons only after the end of the acute injury, and that this uPA does not have an effect on cell survival. Instead, we show that uPA promotes destructural reorganization in the peri-infarct cortex that underlies neurological recovery after an ischemic injury.

The analysis of the ability of molecules of water to diffuse in the brain (MD) and the directionality of this movement $(\mathrm{Fa})$ are useful tools to study microscopic structures of the neural tissue (Le Bihan, 2003). The MD decreases and the Fa increases when water molecules are in contact with tissue boundaries such as cell membranes (Silva et al., 2002; Sotak, 2002) or dendritic protrusions (Vestergaard-Poulsen et al., 2011; Ding et al., 2013). Our data indicate that $24 \mathrm{~h}$ after tMCAO the MD and $\mathrm{Fa}$ in the necrotic core are similar in $\mathrm{uPA}^{-1-}$ and their Wt-littermate con- trols. These results agree with our observations that the volume of the necrotic core is similar in both strains of mice, and that genetic deficiency of uPA does not confer resistance against hypoxia- and ischemia-induced neuronal death. In contrast, we found that compared with $\mathrm{Wt}$ animals, $\mathrm{uPA}^{-1-}$ mice exhibit an increase in MD and decrease in Fa in the peri-infarct cortex. This increase in the ability of water to diffuse through the peri-infarct tissue with reduction in its directionality is not produced by attenuation of vasogenic edema, or decrease in neuronal population. Instead, it seems to be associated with a decrease in the length of distal neurites and lack of dendritic spine recovery in $\mathrm{uPA}^{-1-}$ mice. Nevertheless, we acknowledge that it is also likely that variations in the population of other cell types such as endothelial and inflammatory cells may also contribute to the reported changes in water diffusivity in $\mathrm{uPA}^{-1-}$ animals.

According to their morphology, dendritic protrusions are classified in filopodia, short spines without a well defined neck, and spines with a large bulbous head (Hering and Sheng, 2001). In the developing brain dendritic spines arise from filopodia (Xu et al., 2009). Our data are in agreement with reports by other groups (Brown et al., 2008) and suggest that in the peri-infarct cortex of the adult brain the formation of filopodia is a transient event that temporally precedes the re-emergence of dendritic spines. However, we acknowledge that due to methodological limitations we cannot state that the filopodia that we observe in $\mathrm{Wt}$ mice $24 \mathrm{~h}$ after stroke gives origin to the dendritic spines detected $7 \mathrm{~d}$ later. Independently of these limitations, our results suggest that uPA-uPAR binding plays a central role in the recovery of dendritic spines after an ischemic stroke.

We found that the effect of uPA on the recovery of dendritic protrusions and neurological function following an ischemic stroke is mediated by its receptor uPAR. UPAR is a glycosylphosphatidyl inositol-anchored cell membrane protein that regulates the conversion of plasminogen into plasmin at the cell surface and activates cell-signaling pathways that mediate multiple physiological processes including cell migration, adhesion, proliferation, and differentiation (Blasi and Carmeliet, 2002). It has been reported that in the brain uPAR plays a central role in the development of interneurons (Powell et al., 2003). Here we show that under physiological conditions a subset of cortical neurons expresses UPAR diffusely in axons and dendrites.

In the early phases of cerebral ischemia dendritic spines are replaced by areas of focal swelling (varicosities), and during the recovery phase dendritic filopodia re-emerge from these varicosities (Hasbani et al., 2001; Ikegaya et al., 2001; Zhang et al., 2005; Brown et al., 2007, 2008). We found that the re-emergence of dendritic protrusions occurs within 18-24 h of reperfusion following $60 \mathrm{~min}$ of focal cerebral ischemia. These observations are in contrast with those reported by others showing dendritic spine recovery within minutes of reperfusion (Zhang et al., 2005; Murphy et al., 2008). We believe that this discrepancy may be explained at least in part not only by methodological differences but also by the induction of a more extensive and severe ischemic lesion in our work (60 min of tMCAO) compared with a less severe and more circumscribed damage produced by $8 \mathrm{~min}$ of global ischemia (Murphy et al., 2008).

We found that uPAR clusters in dendritic varicosities during the recovery phase of an excitotoxic injury. Remarkably, we detected UPAR expression in the neck and head of dendritic filopodia re-emerging from these varicosities during the recovery phase. These observations agree with previous reports indicating that binding of uPA to uPAR promotes uPAR dimerization (Si- 
trin et al., 2000), and suggest that the interaction between uPA and UPAR guides the re-emergence of dendritic filopodia following an acute ischemic injury. Our data showing that $\mathrm{uPA}^{-1-}$ mice fail to form filopodia from dendritic varicosities, and that treatment with ruPA induces the re-emergence of filopodia in $\mathrm{Wt}$ and $\mathrm{uPA}^{-1-}$ but not in $\mathrm{uPAR}^{-1-}$ neurons further supports this hypothesis. Furthermore, the lack of dendritic spine recovery in Plau GFDhu/GFDhu mice, in which the interaction between uPA and uPAR is abrogated (Connolly et al., 2010), indicates that the effect of endogenous uPA requires its binding to uPAR.

Monomeric (G-actin) and filamentous (F-actin) components are the major cytoskeletal components of dendritic protrusions (Landis and Reese, 1983; Hotulainen and Hoogenraad, 2010). The actin pool is at the tip of the dendritic spine treadmills, generating an expansive force in its head that leads to protrusion growth (Hering and Sheng, 2001). Our findings indicate that uPA drives this process in dendritic protrusions, shifting the actin pool from G-actin to F-actin with formation of dendritic filaments and re-emergence of filopodia and spines during the recovery phase of an acute ischemic injury. These data agree with observations by others in a different experimental system indicating that uPA anchors uPAR to the actin cytoskeleton (Bernstein et al., 2004) and that treatment with uPA redistributes F-actin to the leading edge of migrating cells ( Kjøller and Hall, 2001).

The formation of filopodia requires the addition of actin monomers to the barbed ends of the actin filament and inhibition of depolymerization at the pointed end (Le Clainche and Carlier, 2008). Profilin induces the polymerization of the barbed end of dendritic spines by changing actin nucleotides from ADP to ATP (Pollard and Borisy, 2003), whereas cofilin induces depolymerization and severing of actin filaments from their pointed ends (Hotulainen et al., 2005). The importance of profilin and cofilin in the elongation of dendritic filopodia is underscored by the observation that depletion of cofilin induces stabilization of actin filaments whereas profilin antagonism destabilizes spine structure (Ackermann and Matus, 2003). Our data show that uPA induces the rapid accumulation of profilin in dendritic spines, followed by inactivation of cofilin and elongation and stabilization of dendritic filopodia. This effect is independent of uPA's proteolytic activity, requires uPA's binding to UPAR, and is mediated by Rac, a member of the Rho family of GTPases known to regulate rapid changes in dendritic spine morphology (Tashiro et al., 2000).

We acknowledge that our experimental data do not demonstrate a definitive cause-effect relation between dendritic spine recovery and functional improvement after stroke. However, since the formation of dendritic spines is the anatomical basis of synaptic plasticity (Yuste and Bonhoeffer, 2001), and because synaptic plasticity underlies functional recovery after ischemic stroke (Murphy and Corbett, 2009), we believe that our results suggest that $\mathrm{UPA}-\mathrm{uPAR}$ binding promotes neurological improvement after ischemic stroke via its ability to induce dendritic spine recovery in the peri-infarct cortex. In summary, here we propose a model where the release of uPA from the presynaptic compartment during the recovery phase of an acute ischemic injury induces the clustering of UPAR within varicosities in the postsynaptic compartment (dendrites). The binding of uPA to UPAR in these areas of focal swelling induces the formation and stabilization of F-actin leading to the re-emergence of dendritic protrusions. Our data indicate that uPA- uPAR binding promotes synaptic reorganization and neurological recovery following an acute ischemic stroke.

\section{References}

Ackermann M, Matus A (2003) Activity-induced targeting of profilin and stabilization of dendritic spine morphology. Nat Neurosci 6:1194-1200. CrossRef Medline

Alfano D, Franco P, Vocca I, Gambi N, Pisa V, Mancini A, Caputi M, Carriero MV, Iaccarino I, Stoppelli MP (2005) The urokinase plasminogen activator and its receptor: role in cell growth and apoptosis. Thromb Haemost 93:205-211. Medline

Benveniste H, Drejer J, Schousboe A, Diemer NH (1984) Elevation of the extracellular concentrations of glutamate and aspartate in rat hippocampus during transient cerebral ischemia monitored by intracerebral microdialysis. J Neurochem 43:1369-1374. CrossRef Medline

Bernstein AM, Greenberg RS, Taliana L, Masur SK (2004) Urokinase anchors uPAR to the actin cytoskeleton. Invest Ophthal Vis Sci 45:29672977. CrossRef Medline

Blasi F, Carmeliet P (2002) uPAR: a versatile signalling orchestrator. Nat Rev Mol Cell Biol 3:932-943. CrossRef Medline

Bouët V, Freret T, Toutain J, Divoux D, Boulouard M, Schumann-Bard P (2007) Sensorimotor and cognitive deficits after transient middle cerebral artery occlusion in the mouse. Exp Neurol 203:555-567. CrossRef Medline

Brown CE, Li P, Boyd JD, Delaney KR, Murphy TH (2007) Extensive turnover of dendritic spines and vascular remodeling in cortical tissues recovering from stroke. J Neurosci 27:4101-4109. CrossRef Medline

Brown CE, Wong C, Murphy TH (2008) Rapid morphologic plasticity of peri-infarct dendritic spines after focal ischemic stroke. Stroke 39:12861291. CrossRef Medline

Carmichael ST (2006) Cellular and molecular mechanisms of neural repair after stroke: making waves. Ann Neurol 59:735-742. CrossRef Medline

Castro-Alamancos MA, Borrel J (1995) Functional recovery of forelimb response capacity after forelimb primary motor cortex damage in the rat is due to the reorganization of adjacent areas of cortex. Neuroscience 68: 793-805. CrossRef Medline

Cho E, Lee KJ, Seo JW, Byun CJ, Chung SJ, Suh DC, Carmeliet P, Koh JY, Kim JS, Lee JY (2012) Neuroprotection by urokinase plasminogen activator in the hippocampus. Neurobiol Dis 46:215-224. CrossRef Medline

Connolly BM, Choi EY, Gårdsvoll H, Bey AL, Currie BM, Chavakis T, Liu S, Molinolo A, Ploug M, Leppla SH, Bugge TH (2010) Selective abrogation of the uPA-uPAR interaction in vivo reveals a novel role in suppression of fibrin-associated inflammation. Blood 116:1593-1603. CrossRef Medline

Del Bigio MR, Hosain S, Altumbabic M (1999) Localization of urokinasetype plasminogen activator, its receptor, and inhibitors in mouse forebrain during postnatal development. Int J Dev Neurosci 17:387-399. CrossRef Medline

Dent MA, Sumi Y, Morris RJ, Seeley PJ (1993) Urokinase-type plasminogen activator expression by neurons and oligodendrocytes during process outgrowth in developing rat brain. Eur J Neurosci 5:633-647. CrossRef Medline

Dijkhuizen RM, Ren J, Mandeville JB, Wu O, Ozdag FM, Moskowitz MA, Rosen BR, Finklestein SP (2001) Functional magnetic resonance imaging of reorganization in rat brain after stroke. Proc Natl Acad Sci U S A 98:12766-12771. CrossRef Medline

Ding AY, Li Q, Zhou IY, Ma SJ, Tong G, McAlonan GM, Wu EX (2013) MR diffusion tensor imaging detects rapid microstructural changes in amygdala and hippocampus following fear conditioning in mice. PLoS One 8:e51704. CrossRef Medline

Echeverry R, Wu J, Haile WB, Guzman J, Yepes M (2010) Tissue-type plasminogen activator is a neuroprotectant in the mouse hippocampus. J Clin Invest 120:2194-2205. CrossRef Medline

Go AS, Mozaffarian D, Roger VL, Benjamin EJ, Berry JD, Blaha MJ, Dai S, Ford ES, Fox CS, Franco S, Fullerton HJ, Gillespie C, Hailpern SM, Heit JA, Howard VJ, Huffman MD, Judd SE, Kissela BM, Kittner SJ, Lackland DT, et al. (2014) Heart disease and stroke statistics-2014 update: a report from the American Heart Association. Circulation 129:e28-e292. CrossRef Medline

Hasbani MJ, Schlief ML, Fisher DA, Goldberg MP (2001) Dendritic spines lost during glutamate receptor activation reemerge at original sites of synaptic contact. J Neurosci 21:2393-2403. Medline

Heasman SJ, Ridley AJ (2008) Mammalian Rho GTPases: new insights into their functions from in vivo studies. Nat Rev Mol Cell Biol 9:690-701. CrossRef Medline 
Hering H, Sheng M (2001) Dendritic spines: structure, dynamics and regulation. Nat Rev Neurosci 2:880-888. CrossRef Medline

Honig MG, Hume RI (1989a) Dil and diO: versatile fluorescent dyes for neuronal labelling and pathway tracing. Trends Neurosci 12:333-335, 340-341. CrossRef Medline

Honig MG, Hume RI (1989b) Carbocyanine dyes. Novel markers for labelling neurons. Trends Neurosci 12:336-338. Medline

Hotulainen P, Hoogenraad CC (2010) Actin in dendritic spines: connecting dynamics to function. J Cell Biol 189:619-629. CrossRef Medline

Hotulainen P, Paunola E, Vartiainen MK, Lappalainen P (2005) Actindepolymerizing factor and cofilin-1 play overlapping roles in promoting rapid F-actin depolymerization in mammalian nonmuscle cells. Mol Biol Cell 16:649-664. Medline

Ikegaya Y, Kim JA, Baba M, Iwatsubo T, Nishiyama N, Matsuki N (2001) Rapid and reversible changes in dendrite morphology and synaptic efficacy following NMDA receptor activation: implication for a cellular defense against excitotoxicity. J Cell Sci 114:4083-4093. Medline

Jaillard A, Martin CD, Garambois K, Lebas JF, Hommel M (2005) Vicarious function within the human primary motor cortex? A longitudinal fMRI stroke study. Brain 128:1122-1138. CrossRef Medline

Jiang H, van Zijl PC, Kim J, Pearlson GD, Mori S (2006) DtiStudio: resource program for diffusion tensor computation and fiber bundle tracking. Comput Methods Programs Biomed 81:106-116. CrossRef Medline

Kasai H, Matsuzaki M, Noguchi J, Yasumatsu N, Nakahara H (2003) Structure-stability-function relationships of dendritic spines. Trends Neurosci 26:360-368. CrossRef Medline

Kim BG, Dai HN, McAtee M, Vicini S, Bregman BS (2007) Labeling of dendritic spines with the carbocyanine dye DiI for confocal microscopic imaging in lightly fixed cortical slices. J Neurosci Methods 162:237-243. CrossRef Medline

Kjøller L, Hall A (2001) Rac mediates cytoskeletal rearrangements and increased cell motility induced by urokinase-type plasminogen activator receptor binding to vitronectin. J Cell Biol 152:1145-1157. CrossRef Medline

Landis DM, Reese TS (1983) Cytoplasmic organization in cerebellar dendritic spines. J Cell Biol 97:1169-1178. CrossRef Medline

Le Bihan D (2003) Looking into the functional architecture of the brain with diffusion MRI. Nat Rev Neurosci 4:469-480. CrossRef Medline

Le Clainche C, Carlier MF (2008) Regulation of actin assembly associated with protrusion and adhesion in cell migration. Physiol Rev 88:489-513. CrossRef Medline

Li P, Murphy TH (2008) Two-photon imaging during prolonged middle cerebral artery occlusion in mice reveals recovery of dendritic structure after reperfusion. J Neurosci 28:11970-11979. CrossRef Medline

Murakoshi H, Wang H, Yasuda R (2011) Local, persistent activation of Rho GTPases during plasticity of single dendritic spines. Nature 472:100-104. CrossRef Medline

Murphy TH, Corbett D (2009) Plasticity during stroke recovery: from synapse to behaviour. Nat Rev Neurosci 10:861-872. CrossRef Medline

Murphy TH, Li P, Betts K, Liu R (2008) Two-photon imaging of stroke onset in vivo reveals that NMDA-receptor independent ischemic depolarization is the major cause of rapid reversible damage to dendrites and spines. J Neurosci 28:1756-1772. CrossRef Medline

Nagai N, De Mol M, Lijnen HR, Carmeliet P, Collen D (1999) Role of plasminogen system components in focal cerebral ischemic infarction: a gene targeting and gene transfer study in mice. Circulation 99:2440-2444. CrossRef Medline

NSA (2013) Rehabilitation therapy after stroke. National Stroke Association, Centennial, Colorado. In http://www.stroke.org/site/PageServer? pagename $=$ REHABT .

Paxinos G, Franklin KBJ (2001) The mouse brain in stereotaxic coordinates. San Diego, CA: Academic.

Pollard TD, Borisy GG (2003) Cellular motility driven by assembly and disassembly of actin filaments. Cell 112:453-465. CrossRef Medline

Powell EM, Campbell DB, Stanwood GD, Davis C, Noebels JL, Levitt P (2003) Genetic disruption of cortical interneuron development causes region- and GABA cell type-specific deficits, epilepsy, and behavioral dysfunction. J Neurosci 23:622-631. Medline

Samson AL, Medcalf RL (2006) Tissue-type plasminogen activator: a multifaceted modulator of neurotransmission and synaptic plasticity. Neuron 50:673-678. CrossRef Medline
Schneider CA, Rasband WS, Eliceiri KW (2012) NIH Image to ImageJ: 25 years of image analysis. Nat Methods 9:671-675. CrossRef Medline

Silva MD, Omae T, Helmer KG, Li F, Fisher M, Sotak CH (2002) Separating changes in the intracellular and extracellular water apparent diffusion coefficient following focal cerebral ischemia in the rat brain. Magn Reson Med 48:826-837. CrossRef Medline

Sitrin RG, Pan PM, Harper HA, Todd RF 3rd, Harsh DM, Blackwood RA (2000) Clustering of urokinase receptors (uPAR; CD87) induces proinflammatory signaling in human polymorphonuclear neutrophils. J Immunol 165:3341-3349. CrossRef Medline

Sotak CH (2002) The role of diffusion tensor imaging in the evaluation of ischemic brain injury-a review. NMR Biomed 15:561-569. CrossRef Medline

Swanger SA, Yao X, Gross C, Bassell GJ (2011) Automated 4D analysis of dendritic spine morphology: applications to stimulus-induced spine remodeling and pharmacological rescue in a disease model. Mol Brain 4:38. CrossRef Medline

Swanson RA, Morton MT, Tsao-Wu G, Savalos RA, Davidson C, Sharp FR (1990) A semiautomated method for measuring brain infarct volume. J Cereb Blood Flow Metab 10:290-293. CrossRef Medline

Tashiro A, Minden A, Yuste R (2000) Regulation of dendritic spine morphology by the rho family of small GTPases: antagonistic roles of Rac and Rho. Cereb Cortex 10:927-938. CrossRef Medline

Tennant KA, Adkins DL, Donlan NA, Asay AL, Thomas N, Kleim JA, Jones TA (2011) The organization of the forelimb representation of the C57BL/6 mouse motor cortex as defined by intracortical microstimulation and cytoarchitecture. Cereb Cortex 21:865-876. CrossRef Medline

Thornton P, Pinteaux E, Allan SM, Rothwell NJ (2008) Matrix metalloproteinase-9 and urokinase plasminogen activator mediate interleukin-1-induced neurotoxicity. Mol Cell Neurosci 37:135-142. CrossRef Medline

Tucker HM, Kihiko M, Caldwell JN, Wright S, Kawarabayashi T, Price D, Walker D, Scheff S, McGillis JP, Rydel RE, Estus S (2000) The plasmin system is induced by and degrades amyloid-beta aggregates. J Neurosci 20:3937-3946. Medline

Vestergaard-Poulsen P, Wegener G, Hansen B, Bjarkam CR, Blackband SJ, Nielsen NC, Jespersen SN (2011) Diffusion-weighted MRI and quantitative biophysical modeling of hippocampal neurite loss in chronic stress. PLoS One 6:e20653. CrossRef Medline

Wang JY, Abdi H, Bakhadirov K, Diaz-Arrastia R, Devous MD Sr, Sr (2012) A comprehensive reliability assessment of quantitative diffusion tensor tractography. Neuroimage 60:1127-1138. CrossRef Medline

Wu F, Wu J, Nicholson AD, Echeverry R, Haile WB, Catano M, An J, Lee AK, Duong D, Dammer EB, Seyfried NT, Tong FC, Votaw JR, Medcalf RL, Yepes M (2012) Tissue-type plasminogen activator regulates the neuronal uptake of glucose in the ischemic brain. J Neurosci 32:9848-9858. CrossRef Medline

Wu F, Echeverry R, Wu J, An J, Haile WB, Cooper DS, Catano M, Yepes M (2013a) Tissue-type plasminogen activator protects neurons from excitotoxin-induced cell death via activation of the ERK1/2-CREB-ATF3 signaling pathway. Mol Cell Neurosci 52:9-19. CrossRef Medline

Wu F, Nicholson AD, Haile WB, Torre E, An J, Chen C, Lee AK, Duong DM, Dammer EB, Seyfried NT, Tong FC, Votaw JR, Yepes M (2013b) Tissuetype plasminogen activator mediates neuronal detection and adaptation to metabolic stress. J Cereb Blood Flow Metab 33:1761-1769. CrossRef Medline

Xu T, Yu X, Perlik AJ, Tobin WF, Zweig JA, Tennant K, Jones T, Zuo Y (2009) Rapid formation and selective stabilization of synapses for enduring motor memories. Nature 462:915-919. CrossRef Medline

Yepes M, Sandkvist M, Wong MK, Coleman TA, Smith E, Cohan SL, Lawrence DA (2000) Neuroserpin reduces cerebral infarct volume and protects neurons from ischemia-induced apoptosis. Blood 96:569-576. Medline

Yepes M, Sandkvist M, Moore EG, Bugge TH, Strickland DK, Lawrence DA (2003) Tissue-type plasminogen activator induces opening of the bloodbrain barrier via the LDL receptor-related protein. J Clin Invest 112:15331540. CrossRef Medline

Yuste R, Bonhoeffer T (2001) Morphological changes in dendritic spines associated with long-term synaptic plasticity. Annu Rev Neurosci 24: 1071-1089. CrossRef Medline

Zhang S, Boyd J, Delaney K, Murphy TH (2005) Rapid reversible changes in dendritic spine structure in vivo gated by the degree of ischemia. J Neurosci 25:5333-5338. CrossRef Medline 